\title{
Modelling of Running Performances: Comparisons of Power-Law, Hyperbolic, Logarithmic, and Exponential Models in Elite Endurance Runners
}

\author{
H. Vandewalle \\ UFR de Santé, Médecine et Biologie Humaine, Université Paris XIII, Bobigny, France \\ Correspondence should be addressed to H. Vandewalle; henry.vandewalle@club-internet.fr
}

Received 1 April 2018; Revised 2 August 2018; Accepted 2 September 2018; Published 3 October 2018

Academic Editor: Ronald E. Baynes

Copyright (C) 2018 H. Vandewalle. This is an open access article distributed under the Creative Commons Attribution License, which permits unrestricted use, distribution, and reproduction in any medium, provided the original work is properly cited.

Many empirical and descriptive models have been proposed since the beginning of the $20^{\text {th }}$ century. In the present study, the powerlaw (Kennelly) and logarithmic (Péronnet-Thibault) models were compared with asymptotic models such as 2-parameter hyperbolic models (Hill and Scherrer), 3-parameter hyperbolic model (Morton), and exponential model (Hopkins). These empirical models were compared from the performance of 6 elite endurance runners (P. Nurmi, E. Zatopek, J. Väätäinen, L. Virén, S. Aouita, and H. Gebrselassie) who were world-record holders and/or Olympic winners and/or world or European champions. These elite runners were chosen because they participated several times in international competitions over a large range of distances $(1500,3000,5000$, and $10000 \mathrm{~m}$ ) and three also participated in a marathon. The parameters of these models were compared and correlated. The less accurate models were the asymptotic 2-parameter hyperbolic models but the most accurate model was the asymptotic 3-parameter hyperbolic model proposed by Morton. The predictions of long-distance performances (maximal running speeds for 30 and 60 min and marathon) by extrapolation of the logarithmic and power-law models were more accurate than the predictions by extrapolation in all the asymptotic models. The overestimations of these long-distance performances by Morton's model were less important than the overestimations by the other asymptotic models.

\section{Introduction}

Many models [1-11] of running performances based on biomechanics and physiology have been proposed. These models are generally complex. For example, the physiological model proposed by Péronnet and Thibault [7] included the inertia, power, and capacity of the anaerobic and aerobic metabolisms.

Empirical and descriptive models have also been proposed since the beginning of the $20^{\text {th }}$ century and presented in many reviews [12-21]. Empirical models are derived by observation and experimentation rather than by theoretical considerations [14]. The empirical models are less complex than the biomechanical and physiological models but are also less explicative. The most famous empirical models corresponded to a power-law model (Kennelly, 1906), asymptotic hyperbolic models (Hill, 1927; Scherrer, 1954), and, more recently, a logarithmic model (Péronnet and Thibault, 1987) and 3-parameter asymptotic models (Hopkins, 1989; Morton, 1996). The asymptotic models correspond to horizontal asymptote equations: the functions approach a horizontal line when $t_{\lim }$ tends to infinity. In these models, it is assumed that the speeds lower than these asymptotes can be maintained infinitely.

The empirical models of running exercises are often used to estimate

(i) the improvement in performance [22]

(ii) the effects of age $[23,24]$ and sex $[25,26]$ on running performance

(iii) the future performances and running speeds over given distances

(iv) the endurance capability $[7,8]$, that is, "the ability to sustain a high fractional utilization of maximal oxygen uptake for a prolonged period of time" 
TABLE 1: Individual performances (in seconds) of elite endurance runners.

\begin{tabular}{lccccc}
\hline & 1500 & 3000 & 5000 & 10000 & Marathon \\
\hline Nurmi & 233 & 500 & 868 & 1806 & 1734 \\
Zatopek & 233 & 488 & 837 & 1672 & 8583 \\
Väätäinen & 224 & 473 & 808 & 1658 & 7991 \\
Virén & 222 & 463 & 796 & 1646 & \\
Aouita & 209 & 449 & 778 & 1583 & 7439 \\
Gebrselassie & 214 & 445 & 759 & & \\
\hline
\end{tabular}

(v) the speed of training sessions [27]

(vi) the maximal aerobic speed $[7,8]$

The maximal aerobic speed, otherwise known as MAS, is the lowest running speed at which maximum oxygen uptake (V02 max) occurs, and is also referred to as the velocity at V02 max (vV02 max). MAS is useful for training prescription and monitoring training loads. Péronnet and Thibault suggested estimating MAS by computing the maximal speed corresponding to $7 \mathrm{~min}$ [8]. The maximal lactate steady state, defined as the highest constant power output that can be maintained without a progressive increase in blood lactate concentration, is usually sustainable for 30 to $60 \mathrm{~min}$. [2830].

The first studies on the modelling of running performances were based on the world records because these records measured under standard external conditions represent the most reliable index of human performance $[31,32]$. The running times of the slower runners are more variable than those of the faster runners [33]. The best performances of world elite runners are probably very close to their maximal performances because they generally correspond to the results of many competitions against other elite runners and the motivation is probably optimal during these races. Now, the best performances of elite endurance runners who ran on different distances and were the best of their times can be found on the Internet (Wikipedia, etc.). Therefore, it is possible to study the characteristics of the different models which have been proposed for endurance exercises with the best performances of elite endurance runners.

The performances of different runners were used in each study on the modelling of world and Olympic records [7, $22,31,32,34,35]$. In contrast, in the present investigation, each model was computed only from the performances of a single runner. The computations of each model were repeated for different world elite endurance runners ( $P$. Nurmi, E. Zatopek, J. Väätäinen, L. Virén, S. Aouita, and H. Gebrselassie) who were world-record holders and/or Olympic winners and/or world or European champions. They participated several times in international competitions over the same distances $(1500,3000,5000$, and $10000 \mathrm{~m}$ ) that corresponded to a large range of distances. Their best individual performances are presented in Table 1.

Moreover, if a model is not perfect for a large range of performances, the values of its parameters computed from different ranges of distances will be significantly different. In the present study, the parameters of the different models were computed with 3 ranges of distances: (i) 1500-3000-5000-10000 $\mathrm{m}$ for the largest range

(ii) $1500-3000-5000 \mathrm{~m}$, which is equivalent to the range of $t_{\lim }$ generally used in the studies on critical speed or critical power (from 3 to $15 \mathrm{~min}$ )

(iii) 3000-5000-10000 m, which corresponds to exercises slower than maximal aerobic speed

Several previous investigations studied the evolution of the parameters in the models of running performances at different times [22, 34]. Similarly, the six elite endurance athletes of the present study ran at different times and their performances were performed in different conditions (cinder tracks versus synthetic tracks, nutrition, etc.) and were the results of different running exercises (for example, an equivalent of fartleck for Nurmi, an equivalent of intervaltraining for Zatopek, and altitude training for Gebrselassié), which could partly explain the evolution of the performances in these world elite runners and could also change the best model of individual running performances.

The present study (1) applied the power-law and logarithmic models and four asymptotic models (two 2-parameter hyperbolic models, a 3-parameter hyperbolic model, and a 3-parameter exponential model) to the individual performances of the elite runners, (2) compared the accuracy of these models and the effects of the range of performances on their parameters to assess which is the best model, and (3) compared the predictions of MAS by interpolation and the prediction of maximal running speeds for long distances (30, $60 \mathrm{~min}$ and also marathon in 3 runners) by extrapolation.

\section{History of the Power-Law, Hyperbolic, Logarithmic, and Exponential Models}

2.1. Power-Law Model (Kennelly). In 1906, Kennelly [12] studied the relationship between running speed (S) and the time of the world records $\left(\mathrm{t}_{\lim }\right)$ and proposed a power law:

$$
\mathrm{D}_{\text {lim }}=\mathrm{kt}_{\text {lim }}^{\mathrm{g}}
$$

where $\mathrm{k}$ is a constant and $\mathrm{g}$ an exponent. This power law between distance and time corresponds to a power law between time and speed $(\mathrm{S})$ :

$$
\mathrm{S}=\frac{\mathrm{D}_{\lim }}{\mathrm{t}_{\lim }}=\frac{\mathrm{kt}_{\text {lim }}{ }^{\mathrm{g}}}{\mathrm{t}_{\lim }}=\mathrm{kt}_{\text {lim }} \mathrm{g} \mathrm{-1}
$$

Exponent $\mathrm{g}$ is probably an expression of endurance capability. Indeed, the $t_{\text {lim }}-D_{\text {lim }}$ relationship would be perfectly linear if 
$\mathrm{g}$ is equal to 1 . It is likely that the curvatures of the $t_{\text {lim }}-S$ and $t_{\text {lim }}-D_{\text {lim }}$ relationships depend on the decrease in the fraction of maximal aerobic metabolism that can be sustained during long lasting exercises. The value of exponent $g$ is independent of scaling as it is independent of the expression of $t_{\text {lim }}, S$, and $\mathrm{D}_{\text {lim }}$.

In theory, parameter $\mathrm{k}$ should be correlated to maximal running speed because $\mathrm{k}$ is equal to the maximal running speed corresponding to one second. Indeed, when $t_{\text {lim }}$ is equal to $1 \mathrm{~s}$

$$
\mathrm{S}=\mathrm{kt}_{\lim }{ }^{\mathrm{g}-1}=\mathrm{k} * 1^{\mathrm{g}-1}=\mathrm{k} * 1=\mathrm{k}
$$

In 1981, a similar power-law model was proposed by Riegel [36]:

$$
\begin{aligned}
\mathrm{t}_{\lim } & =\mathrm{aD}_{\lim }{ }^{\mathrm{b}} \\
\mathrm{S} & =\frac{\mathrm{D}_{\lim }}{\mathrm{t}_{\lim }}=\frac{\mathrm{D}_{\lim }}{\mathrm{aD}_{\lim } \mathrm{b}}=\frac{\left(\mathrm{D}_{\lim }{ }^{1-\mathrm{b}}\right)}{\mathrm{a}}
\end{aligned}
$$

As $\mathrm{D}_{\text {lim }}=\mathrm{kt}_{\text {lim }}{ }^{\mathrm{g}}$

$$
\begin{aligned}
\mathrm{D}_{\lim }{ }^{1 / g} & =\left(\mathrm{kt}_{\lim }{ }^{\mathrm{g}}\right)^{1 / \mathrm{g}}=\mathrm{k}^{1 / \mathrm{g}_{\mathrm{lim}}} \\
\mathrm{t}_{\lim } & =\frac{\mathrm{D}_{\lim }{ }^{1 / \mathrm{g}}}{\mathrm{k}^{1 / \mathrm{g}}}=\frac{\left(\mathrm{D}_{\lim }{ }^{1-\mathrm{b}}\right)}{\mathrm{a}} \\
\mathrm{a} & =\mathrm{k}^{1 / \mathrm{g}}
\end{aligned}
$$

and

$$
\begin{aligned}
\mathrm{D}_{\lim }{ }^{1 / \mathrm{g}} & =\left(\mathrm{D}_{\lim }{ }^{1-\mathrm{b}}\right) \\
\frac{1}{\mathrm{~g}} & =1-\mathrm{b} \\
\mathrm{b} & =1-\frac{1}{\mathrm{~g}}=\frac{(\mathrm{g}-1)}{\mathrm{g}}
\end{aligned}
$$

These equations of Riegel have recently been applied to a large study on 2303 recreational endurance runners [37].

2.2. Hyperbolic Model (Hill, Scherrer). In 1927, Hill [1] proposed a hyperbolic model to describe the world-record curve in running and swimming. Hill observed that the "running curve," or the relationship between a runner's power output $(\mathrm{P})$ and the total duration of a race $(\mathrm{T})$, can be described by a hyperbolic function:

$$
\mathrm{P}=\left(\frac{\mathrm{A}}{\mathrm{T}}\right)+\mathrm{R}
$$

where $\mathrm{A}$ and $\mathrm{R}$ represent the capacity of anaerobic metabolism and the rate of energy release from aerobic metabolism, respectively. In 1954, Scherrer et al. proposed a linear relationship [38] between the exhaustion time $\left(t_{\text {lim }}\right)$ of a local exercise (flexions or extensions of the elbow or the knee) performed at different constant power outputs $(\mathrm{P})$ and the total amount of work performed at exhaustion $\left(\mathrm{W}_{\text {lim }}\right)$ for $t_{\text {lim }}$ ranging between 3 and 30 minutes:

$$
\mathrm{W}_{\lim }=\mathrm{a}+\mathrm{bt}_{\lim }
$$

Consequently, the relationship between $\mathrm{P}$ and $\mathrm{t}_{\text {lim }}$ is hyperbolic:

$$
\begin{aligned}
\mathrm{W}_{\text {lim }} & =\mathrm{Pt}_{\lim }=\mathrm{a}+\mathrm{bt}_{\lim } \\
\mathrm{t}_{\lim } & =\frac{\mathrm{a}}{(\mathrm{P}-\mathrm{b})}
\end{aligned}
$$

After the publication of an article in English (1965) by Monod and Scherrer [39], Ettema (1966) applied the critical-power concept to world records in running, swimming, cycling, and skating exercises [40] and proposed a linear relationship between $\mathrm{D}_{\text {lim }}$ and $\mathrm{t}_{\lim }$ for world records from 1500 to 10000 m:

$$
\mathrm{D}_{\text {lim }}=\mathrm{a}+\mathrm{bt}_{\text {lim }}
$$

where $t_{\text {lim }}$ corresponded to the world record for a given distance $\left(D_{\text {lim }}\right)$. It was assumed that the energy cost of running, i.e., the energy expenditure per unit of distance, was almost independent of speed under $20 \mathrm{~km} \cdot \mathrm{h}^{-1}$. Consequently, $\mathrm{D}_{\text {lim }}$ and parameter a were equivalent to amounts of energy. Therefore, parameter a has been interpreted as equivalent to an energy store and an estimation of maximal Anaerobic Distance Capacity (ADC expressed in metres) for running exercises whereas slope $b$ was considered as a critical velocity $\left(\mathrm{S}_{\text {Crit }}\right)$.

$$
\begin{aligned}
D_{\text {lim }} & =A D C+S_{\text {Crit } 1} t_{\text {lim }} \\
t_{\text {lim }} & =\frac{A D C}{\left(S-S_{\text {Crit1 }}\right)}
\end{aligned}
$$

However, the linear $\mathrm{W}_{\lim }-\mathrm{t}_{\lim }$ was an approximation as indicated by Scherrer and Monod (1960): "The relationship $\mathrm{W}=\mathrm{f}(\mathrm{t})$ is not perfectly linear as shown on Figure 2(a), where the curves tend towards abscissa beyond 30 minutes" [41]. In the study by Ettema in $1966, \mathrm{~S}_{\text {Crit }}$ and ADC depended on the range of $t_{\text {lim }}$, which was confirmed by more recent studies $[42,43]$.

In 1981, the linear $\mathrm{W}_{\text {lim }} \mathrm{t}_{\text {lim }}$ relationship was adapted to exercises on a stationary cycle ergometer and it was demonstrated that slope $\mathrm{b}$ of the $\mathrm{W}_{\text {lim }}-\mathrm{t}_{\text {lim }}$ relationship was highly correlated with the ventilatory threshold [44]. Therefore, slope b was proposed as an indicator of general endurance and the concept of critical power or critical velocity was again studied. Different equations were proposed for the estimation of $\mathrm{S}_{\text {Crit }}$ (or CP). For example, $\mathrm{S}_{\text {Crit }}$ on a treadmill [45] was computed from the linear relationship between $\mathrm{D}_{\lim }$ and the inverse of $t_{\lim }\left(1 / t_{\lim }\right)$ :

$$
\mathrm{S}=\mathrm{a}\left(\frac{1}{\mathrm{t}_{\text {lim }}}\right)+\mathrm{b}=\operatorname{ADC}_{2}\left(\frac{1}{\mathrm{t}_{\text {lim }}}\right)+\mathrm{S}_{\text {Crit2 }}
$$

More recently, Morton [15] proposed a fourth model for the critical power, a nonlinear model including a third parameter corresponding to maximal instantaneous power $\left(\mathrm{P}_{\max }\right)$. This model has been adapted to running exercises with an instantaneous maximal running speed $\left(\mathrm{S}_{\mathrm{Max}}\right)$ :

$$
t_{\lim }=\frac{\mathrm{ADC}_{3}}{\left(\mathrm{~S}-\mathrm{S}_{\mathrm{Crit} 3}\right)}-\frac{\mathrm{ADC}_{3}}{\left(\mathrm{~S}_{\mathrm{Max}}-\mathrm{S}_{\mathrm{Crit} 3}\right)}
$$

Actually, the different asymptotic hyperbolic models are the most used and studied [46]. 
2.3. Logarithmic Model (Péronnet-Thibault). The metabolic model proposed by Péronnet and Thibault $[7,8]$ included factors that took into account the contributions of aerobic and anaerobic metabolism to total energy output according to the duration of the race. The inertia of the aerobic metabolism at the beginning of the exercise was also included in the model. In addition, the use of anaerobic store $S_{A}$ was assumed to decrease beyond $\mathrm{T}_{\mathrm{MAP}}$ (exhaustion time corresponding to maximal aerobic power):

$$
\begin{aligned}
& \mathrm{S}_{\mathrm{A}}=\mathrm{A} \quad \text { for } \mathrm{T} \leq \mathrm{T}_{\mathrm{MAP}} \\
& \mathrm{S}_{\mathrm{A}}=\mathrm{A}-0.233 \mathrm{~A} \ln \left(\frac{\mathrm{T}}{\mathrm{T}_{\mathrm{MAP}}}\right) \text { for } \mathrm{T}>\mathrm{T}_{\mathrm{MAP}}
\end{aligned}
$$

A runner is only capable of sustaining his maximal aerobic power for a finite period of time. The performances in long distance events depend on the ability to utilize a large percentage of $\mathrm{V}_{\mathrm{O} 2} \max$ over a prolonged period of time (endurance capability). Péronnet and Thibault $[7,8]$ assumed that $t_{\lim }$ corresponding to maximal aerobic speed $\left(t_{\text {MAS }}\right)$ is equal to $7 \mathrm{~min}$. They proposed the slope (E) of the relationship between the fractional utilization of MAS and the logarithm of $t_{\text {lim }} / 7 \mathrm{~min}(420 \mathrm{~s})$ as an index of endurance capability:

$$
\begin{aligned}
S & =\mathrm{MAS}-\mathrm{E}_{7 \min } \ln \left(\frac{\mathrm{t}_{\text {lim }}}{420}\right) \\
\frac{100 \mathrm{~S}}{\mathrm{MAS}} & =100-\mathrm{E} \ln \left(\frac{\mathrm{t}_{\lim }}{420}\right)
\end{aligned}
$$

where MAS is the maximal running speed corresponding to $7 \mathrm{~min}$ and $\mathrm{E}$ is the endurance index corresponding to MAS ( $\left.E=100 \mathrm{E}_{7 \mathrm{~min}} / \mathrm{MAS}\right)$. There was a significant correlation between the ventilatory threshold and $E$ in marathon runners [47], which suggested that E was an index of aerobic endurance. The values of $\mathrm{E}$ and $\mathrm{MAS}_{7 \min }$ can be estimated from two running performances with a nomogram [48].

2.4. Exponential Model. Hopkins et al. [13] have presented an asymptotic exponential model for short-duration (10 s - 3 min) running exercises on a treadmill with 5 different slopes (9 to $31 \%)$. This model was

$$
I_{t}=I_{\infty}+\left(I_{0}-I_{\infty}\right) \exp \left(-\frac{t_{\lim }}{\tau}\right)
$$

where $I_{\infty}$ is the slope corresponding to infinite time, $I_{0}$ the slope corresponding to a time equal to zero, $I_{t}$ the slope corresponding to $t_{\text {lim }}$, and $\tau$ is a time constant. This model can be adapted to running exercises on a track:

$$
S=S_{\infty}+\left(S_{0}-S_{\infty}\right) \exp \left(-\frac{t_{\text {lim }}}{\tau}\right)
$$

This asymptotic exponential model derived from Hopkins' model has been used and compared to the different asymptotic hyperbolic models in several studies [49-52].

\section{Methods}

The logarithmic, power-law, and hyperbolic models which are 2-parameter models were computed by linear least-square regressions between time data and speed data (or distance data). Time data correspond to $t_{\text {lim }}$ or the logarithm of $t_{\lim }$. Speed data correspond to speed or the logarithm of speed. The models by Morton and Hopkins are 3-parameter models whose individual regressions were computed by an iterative least square method.

\subsection{Computation of the Empirical Models}

3.1.1. Computation of the Power-Law Model. If $\mathrm{Y}=\mathrm{A} * \mathrm{X}$, the logarithm of $\mathrm{Y}$ is equal to

$$
\ln (\mathrm{Y})=\ln (\mathrm{A})+\ln (\mathrm{X})
$$

If $\mathrm{Y}=\mathrm{X}^{-\mathrm{B}}$, the logarithm of $\mathrm{Y}$ is equal to

$$
\ln (\mathrm{Y})=-\mathrm{B} \ln (\mathrm{X})
$$

If $\mathrm{Y}=\mathrm{A} * \mathrm{X}^{-\mathrm{B}}$, the logarithm of $\mathrm{Y}$ is equal to

$$
\ln (\mathrm{Y})=\ln (\mathrm{A})-\mathrm{B} \ln (\mathrm{X})=\mathrm{C}-\mathrm{B} \ln (\mathrm{X})
$$

where $\mathrm{C}=\ln (\mathrm{A})$ and $\exp (\mathrm{C})=\exp [\ln (\mathrm{A})]=\mathrm{A}$.

Therefore, the power laws between $t_{\lim }$ and $D_{\lim }$ or $S$ can be determined by computing the regression between the natural logarithms of $\mathrm{D}_{\mathrm{lim}}$ and $\mathrm{t}_{\mathrm{lim}}$ :

$$
\begin{aligned}
\ln \left(\mathrm{D}_{\text {lim }}\right) & =\alpha+\gamma \ln \left(\mathrm{t}_{\lim }\right)=\ln (\mathrm{k})+\mathrm{g} \ln \left(\mathrm{t}_{\text {lim }}\right) \\
\mathrm{k} & =\mathrm{e}^{\ln (\mathrm{k})}=\mathrm{e}^{\alpha}
\end{aligned}
$$

3.1.2. Computation of the Hyperbolic Models. In the present study, three estimations of critical velocity $\left(\mathrm{S}_{\mathrm{Crit} 1}, \mathrm{~S}_{\mathrm{Crit} 2}\right.$, and $\mathrm{S}_{\text {Crit3 }}$ ) were computed:

$$
\begin{aligned}
\mathrm{D}_{\text {lim }} & =\mathrm{ADC}_{1}+\mathrm{S}_{\text {Crit } 1} \mathrm{t}_{\text {lim }} \\
\mathrm{Y} & =\alpha_{1}+\beta_{1} \mathrm{X}
\end{aligned}
$$

where $\mathrm{Y}=\mathrm{D}_{\text {lim }} ; \mathrm{X}=\mathrm{t}_{\text {lim }} ; \alpha_{1}=\mathrm{ADC}_{1} ; \beta_{1}=\mathrm{S}_{\mathrm{Crit} 1}$

$$
\begin{aligned}
& \mathrm{S}=\mathrm{a}+\mathrm{b}\left(\frac{1}{\mathrm{t}_{\lim }}\right)=\mathrm{S}_{\mathrm{Crit} 2}+\mathrm{ADC}_{2}\left(\frac{1}{\mathrm{t}_{\mathrm{lim}}}\right) \\
& \mathrm{Y}=\alpha_{2}+\beta_{2} \mathrm{X}
\end{aligned}
$$

where $\mathrm{Y}=\mathrm{S} ; \mathrm{X}=1 / \mathrm{t}_{\text {lim }} ; \alpha_{2}=\mathrm{S}_{\mathrm{Crit} 2} ; \beta_{2}=\mathrm{ADC}_{2}$

In the 3-parameter model by Morton

$$
t_{\lim }=\frac{\mathrm{ADC}_{3}}{\left(\mathrm{~S}-\mathrm{S}_{\mathrm{Crit} 3}\right)}-\frac{\mathrm{ADC}_{3}}{\left(\mathrm{~S}_{\mathrm{Max}}-\mathrm{S}_{\mathrm{Crit3}}\right)}
$$

Let $\mathrm{C}=\mathrm{ADC}_{3} /\left(\mathrm{S}_{\mathrm{Max}}-\mathrm{S}_{\mathrm{Crit} 3}\right)$

$$
\begin{aligned}
t_{\text {lim }} & =\frac{\mathrm{ADC}_{3}}{\left(\mathrm{~S}-\mathrm{S}_{\mathrm{Crit} 3}\right)}-\mathrm{C} \\
\mathrm{S}_{\text {Max }} & =\mathrm{S}_{\text {Crit3 }}+\frac{\mathrm{ADC}_{3}}{\mathrm{C}}
\end{aligned}
$$


First, this equation was computed by an iterative least square method for a hyperbolic decay formula with 3 parameters $\left(\mathrm{Y}_{0}, \mathrm{a}\right.$, and $\left.\mathrm{b}\right)$ :

$$
\mathrm{Y}=\mathrm{Y}_{0}+\frac{\mathrm{ab}}{(\mathrm{x}+\mathrm{b})}
$$

where $\mathrm{Y}_{0}=-\mathrm{C}, \mathrm{b}=-\mathrm{S}_{\mathrm{Crit} 3}$, and $\mathrm{ab}=\mathrm{ADC}_{3}$

Unfortunately, there was no convergence of the iteration. Therefore, an iteration was tested for another equation:

$$
\begin{aligned}
t_{\text {lim }}+\mathrm{C} & =\frac{\mathrm{ADC}_{3}}{\left(\mathrm{~S}-\mathrm{S}_{\mathrm{Crit} 3}\right)} \\
\mathrm{S}-\mathrm{S}_{\text {Crit3 }} & =\frac{\mathrm{ADC}_{3}}{\left(\mathrm{t}_{\text {lim }}+\mathrm{C}\right)} \\
\mathrm{S} & =\mathrm{S}_{\text {Crit3 }}+\frac{\mathrm{ADC}_{3}}{\left(\mathrm{t}_{\text {lim }}+\mathrm{C}\right)}
\end{aligned}
$$

This equation was computed with an iterative least square method for a similar hyperbolic decay formula with 3 parameters $\left(\mathrm{Y}_{0}\right.$, a, and $\left.\mathrm{b}\right)$ :

$$
\mathrm{Y}=\mathrm{Y}_{0}+\frac{\mathrm{ab}}{(\mathrm{x}+\mathrm{b})}
$$

where $\mathrm{Y}=\mathrm{S}, \mathrm{Y}_{0}=\mathrm{S}_{\mathrm{Crit} 3}, \mathrm{ab}=\mathrm{ADC}_{3}$, and $\mathrm{b}=\mathrm{C}$.

As the value of $\mathrm{S}_{\max }=\mathrm{S}_{\mathrm{Crit} 3}+\mathrm{ADC} / \mathrm{C}$

$$
\mathrm{S}_{\max }=\mathrm{Y}_{0}+\frac{\mathrm{ab}}{\mathrm{b}}=\mathrm{Y}_{0}+\mathrm{a}
$$

Fortunately, there was a convergence in the iteration for this equation.

3.1.3. Computation of the Logarithmic Model. The value of $\mathrm{E}$ was estimated by computing the regression between $S$ and the logarithm of $\mathrm{t}_{\lim } / 420$ for the different distances:

$$
S=\alpha-\beta \ln \left(\frac{t_{\lim }}{420}\right)
$$

When $t_{\lim }=420, S$ is equal to MAS and $\ln \left(t_{\lim } / 420\right)$ is equal to 0 . Therefore

$$
\begin{aligned}
& \mathrm{S}=\mathrm{MAS}=\alpha+0 \\
& \mathrm{E}=\frac{100 \beta}{\mathrm{MAS}}=\frac{100 \beta}{\alpha}
\end{aligned}
$$

3.1.4. Computation of the Exponential Model. At least three distances are necessary to compute Hopkins' model (see (19)) which is a three-parameter model $\left(S_{\infty}, a_{1}\right.$, and $\left.b_{1}\right)$ like Morton's model.

$$
\begin{aligned}
S & =S_{\infty}+\left(S_{0}-S_{\infty}\right) \exp \left(-\frac{t_{\text {lim }}}{\tau}\right) \\
& =S_{\infty}+a \exp \left(-b t_{\text {lim }}\right)
\end{aligned}
$$

The regressions were computed by an iterative least square method for a single exponential decay formula with 3 parameters $\left(\mathrm{Y}_{0}, \mathrm{a}\right.$, and $\left.\mathrm{b}\right)$ :

$$
\mathrm{Y}=\mathrm{Y}_{0}+\alpha \exp (-\beta \mathrm{X})
$$

where $\mathrm{X}=\mathrm{t}_{\lim }, \mathrm{Y}_{0}=\mathrm{S}_{\mathrm{\infty}}, \alpha=\mathrm{a}$, and $\beta=\mathrm{b}$
3.2. Estimations of Maximal Running Speeds corresponding to 7, 30, and 60 Minutes. The estimations of the individual maximal running speeds corresponding to 7 minutes (estimation of maximal aerobic speed, MAS) were performed by interpolation from the 1500-3000-5000m performances.

The estimations of the maximal running speed during 30 min were done by extrapolation from the 1500-3000-5000m performances. The 30-min running times were compared with the $10000 \mathrm{~m}$ performances $\left(\mathrm{S}_{10000}\right)$.

The estimations of the maximal running speed during 60 min were done by extrapolation from the 1500-3000-5000$10000 \mathrm{~m}$ performances.

3.3. Accuracy of the Estimations of Running Speed. The individual running speeds corresponding to the different distances (1500, 3000, 5000, and $10000 \mathrm{~m}$ ) were estimated from the individual regressions of the different models and compared with the actual speeds for the same distances. First, for each model, the individual running speeds corresponding to $t_{\text {lim }}$ between 1 and $1900 \mathrm{~s}$ were computed from the individual regressions with an increment equal to $1 \mathrm{~s}$. Secondly, the individual relationships between distance and the estimated value of $t_{\text {lim }}$ were computed by multiplying $t_{\text {lim }}$ and the corresponding estimated speed (distance $=$ speed $\mathrm{x}$ time). Then, the individual estimated values of running speed corresponding to $1500,3000,5000$, and $10000 \mathrm{~m}$ were registered and compared with the actual values of running speeds.

Thereafter, the ratios of estimated speed to actual speed were computed for each distance and each runner.

3.4. Statistics. All the computations of the model and the statistics were performed with the SigmaPlot software (Systat, Chicago, USA).

3.4.1. Comparisons of the Parameters. The comparisons of the parameters, computed from different ranges of distances or from different running models $\left(\mathrm{S}_{\text {Crit1 }}, \mathrm{S}_{\text {Crit2 }}, \mathrm{S}_{\text {Crit3 }}, \mathrm{S}_{\infty}\right.$, $\mathrm{S}_{\mathrm{Max}}$, and $\mathrm{S}_{0}$ ), were studied with a nonparametric paired test (Wilcoxon signed rank test) since the sample sizes were low (6 runners). Significance was accepted at critical $\mathrm{P}<0.05$. The probability was equal to 0.031 in Wilcoxon signed rank test when all the individual values of a parameter are either lower or higher than all the corresponding individual values of a parameter in another model (or another performance range).

3.4.2. Comparison of the Accuracy in the Different Models. In statistics, the sum of the squares of residuals (deviations predicted from actual empirical values of data) is a measure of the discrepancy between the data and an estimation model. A small sum of the squares of residuals indicates a tight fit of the model to the data.

However, in the present study, the comparisons of the accuracy in the different models cannot be based on the differences in the sums of the squares of residuals because the residuals in the power-law model corresponded to the logarithm of the residuals and because the individual regression of the first hyperbolic model $\left(\mathrm{S}_{\mathrm{Crit1}}\right)$ did not correspond to regressions between $t_{\lim }$ and running speeds $(S)$ but 
regressions between $t_{\text {lim }}$ and distances $\left(D_{\text {lim }}\right)$. Moreover, it would be assumed that there was a homoscedasticity in the residuals of the running speeds, which could not be tested with only 4 datasets in an individual regression. In addition, the residuals of computed running speeds could be more important in the faster runners. In the present study, the residuals were computed as equal to the differences between 1 and the ratios of estimated speed to actual speed for each distance and each runner. For a given running model, the squares of these residuals were computed for each distance and each runner, which corresponded to 24 squares (4 distances $\mathrm{x} 6$ runners). The values of the squares of a model were compared with the values of squares for the same distances and same runners in another model. The statistical significance values of the 24 paired differences between two running models were tested with paired Student's $t$-tests after normality tests (Kolmogorov-Smirnov tests). When the normality tests failed, the paired Student's $t$-tests were replaced with the Wilcoxon signed rank tests.

In addition, for each runner, the sum of squared errors for the four distances was computed for each model. The square root of the mean of this sum (root mean square error, RMSE) was computed for each runner and each model. A large error has a disproportionately large effect on RMSE which is, consequently, sensitive to outliers.

\section{Results}

4.1. Power-Law Model Applied to Elite Runners. The effects of the distance range were not significant for exponent $\mathrm{g}(0.063$ $<\mathrm{P}<0.125)$ as well as parameter $\mathrm{k}(0.063<\mathrm{P}<0.094)$.

The estimations of the logarithm of running speeds (S) were close to the logarithm of actual speeds (Figure 1(a)). The correlation coefficients of the individual linear relationships (see $(5))$ between $\ln (S)$ and $\ln \left(t_{\text {lim }}\right)$ or $\ln \left(D_{\text {lim }}\right)$ and $\ln \left(t_{\text {lim }}\right)$ were higher than 0.999 in all the runners for $1500-10000 \mathrm{~m}$.

Similarly, the ratios of estimated to actual speeds (Table 3) for the four distances were accurate: the errors were lower than $1 \%$, except the $10000 \mathrm{~m}$ performance by Nurmi (error equal to $1.1 \%$ ).

Marathon performances were under the extrapolation of the lines of regression computed from the 1500-10000 $\mathrm{m}$ track performances (Figure 1(b)).

\subsection{Hyperbolic Model Applied to Elite Endurance Runners}

4.2.1. $S_{\text {Crit1 }}$ Model. The linear relationships between time $\left(t_{\text {lim }}\right)$ and distance $\left(D_{\text {lim }}\right)$ are presented in Figure 2. For all the runners, the correlation coefficients of the linear regression between $t_{\lim }$ and $\mathrm{D}_{\lim }$ were higher than 0.999 for the different ranges of $\mathrm{D}_{\text {lim }}$. Parameters $\mathrm{S}_{\text {Crit1 }}$ and $\mathrm{ADC}_{1}$ are presented in Table 4. As in previous studies on critical power [42, 43], the values of $S_{\text {Crit1 }}$ depended of the range of $t_{\text {lim }}$. All the differences in $\mathrm{S}_{\text {Crit1 }}$ and $\mathrm{ADC}_{1}$ were significant $(\mathrm{P}=0.031$ in the Wilcoxon signed rank test): the values $S_{\text {Critl }}$ computed from 1500 to $5000 \mathrm{~m}$ were significantly higher than $\mathrm{S}_{\text {Crit1 }}$ computed from 3000 to $10000 \mathrm{~m}$. The ratios of the estimated running speeds to the actual speed estimated from $\mathrm{S}_{\text {Critl }}$ model are presented in Table 5. The errors are moderate $(<$ $2 \%$ ) except for $1500 \mathrm{~m}$.

The values of $\mathrm{ADC}_{1}$ largely depended on the range of performances as shown in Figure 3. When the individual critical speeds decreased because of a change in the range of performances, the corresponding $\mathrm{ADC}_{1}$ increased. These increases in $\mathrm{ADC}_{1}$ were much more important than the decrease in $\mathrm{S}_{\text {Crit1 }}$. For example, $\mathrm{S}_{\text {Crit1 }}$ computed from 3000$10000 \mathrm{~m}$ was $3.8 \%$ lower than $\mathrm{S}_{\text {Crit } 1}$ computed from $1500-5000$ $\mathrm{m}$ (Table 3) whereas the corresponding increase in $\mathrm{ADC}_{1}$ was equal to $79 \%$ ( $319 \pm 53 \mathrm{~m}$ versus $178 \pm 39 \mathrm{~m}$, Figure 3$)$.

4.2.2. $S_{\text {Crit } 2}$ Model. The individual S- $1 / t_{\text {lim }}$ relationships were not linear (Figure 4(a)) when long distances (10 km) were included. The correlation coefficients of the linear regressions between $1 / t_{\lim }$ and $D_{\lim }$ were equal to $0.976 \pm 0.0126$. Parameters $\mathrm{S}_{\mathrm{Crit} 2}$ and $\mathrm{ADC}_{2}$ depended on the range of distances (Table 6). All the differences in $\mathrm{S}_{\mathrm{Crit} 2}$ and $\mathrm{ADC}_{2}$ in function of the distance ranges were significant $(\mathrm{P}=0.031)$. When $\mathrm{S}_{\text {Crit2 }}$ decreased because of a change in the range of performances, the corresponding $\mathrm{ADC}_{2}$ increased. These variations in $\mathrm{ADC}_{2}$ were much more important than the variation in $\mathrm{S}_{\mathrm{Crit} 2}$ (Table 6).

4.2.3. Comparison of the $S_{\text {Crit } 1}$ and $S_{\text {Crit } 2}$ Models. As in previous studies [49-52], the estimates of $S_{\text {Crit }}$ differed according to the mathematical model used to describe the speed- $t_{\text {lim }}$ relationships. The values of $\mathrm{S}_{\mathrm{Crit} 2}$ (Table 6) were significantly higher $(\mathrm{P}=0.031)$ than $\mathrm{S}_{\text {Crit1 }}$ (Table 4$)$. Indeed, the values of $\mathrm{S}_{\mathrm{Crit1}}$ were slightly lower in all the elite endurance runners than the value of $\mathrm{S}_{\mathrm{Crit} 2}$ when they were computed with three (3-5-10km) or four (1.5-3-5-10km) distances (Figure 5(a)). When short distances $(1500 \mathrm{~m})$ were included, the differences between $\mathrm{S}_{\text {Crit1 }}$ and $\mathrm{S}_{\text {Crit2 }}$ increased as demonstrated in Figure 5(a). However, $S_{\text {Crit1 }}$ and $S_{\text {Crit2 }}$ computed from the same range of performance were highly correlated $(\mathrm{P} \geq 0.996)$. The values of $\mathrm{ADC}_{2}$ (Table 6) were significantly lower $(\mathrm{P}=0.031)$ than $\mathrm{ADC}_{1}$ (Table 4) but were significantly correlated $(0.940$ $<\mathrm{r}<0.992 ; \mathrm{P}<0.001)$.

Interestingly, as shown in Figure 5(b), the values of $\mathrm{S}_{\text {Crit1 }}$ were equal to $S_{\text {Crit2 }}$ when both were computed from the same two distances, only (for example, 1.5 and 10 or 3 and $10 \mathrm{~km}$ ). Similarly, $\mathrm{ADC}_{1}$ and $\mathrm{ADC}_{2}$ were equal when both were only computed from the same two distances.

For all the runners, the correlation coefficients for the linear regressions between $1 / t_{\lim }$ and $\mathrm{D}_{\lim }$ in $\mathrm{S}_{\text {Crit2 }}$ model were lower than for the $t_{\text {lim }}-D_{\text {lim }}$ regressions in $S_{\text {Crit1 }}$ model. In contrast, the ratios of estimated to actual speeds (Table 7) were more accurate in the $S_{\text {Crit2 }}$ model: the errors on $1500 \mathrm{~m}$ and RMSE were lower $(\mathrm{P}=0.031)$ than in the $\mathrm{S}_{\mathrm{Crit} 1}$ model. On the other hand, the errors on $10000 \mathrm{~m}$ were higher $(\mathrm{P}=0.031)$ in the $\mathrm{S}_{\mathrm{Crit} 2}$ model.

4.2.4. Morton's Model Applied to Elite Runners. In all the runners, the performances estimated from Morton's model were very close to their actual performances (Figure 6). When the 3-parameter model by Morton was computed with 4 distances (from $1500 \mathrm{~m}$ to $10000 \mathrm{~m}$ ), the correlation coefficient was very high $(0.999 \pm 0.000752)$ in all the 


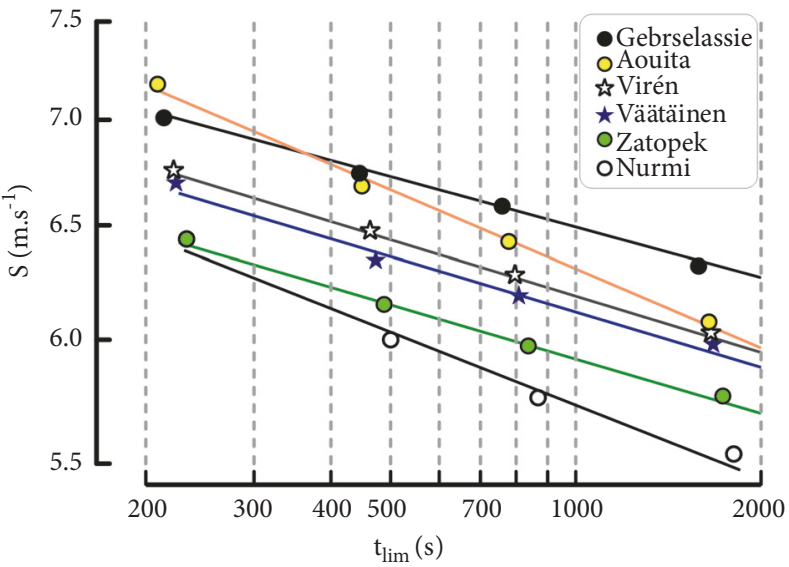

(a)

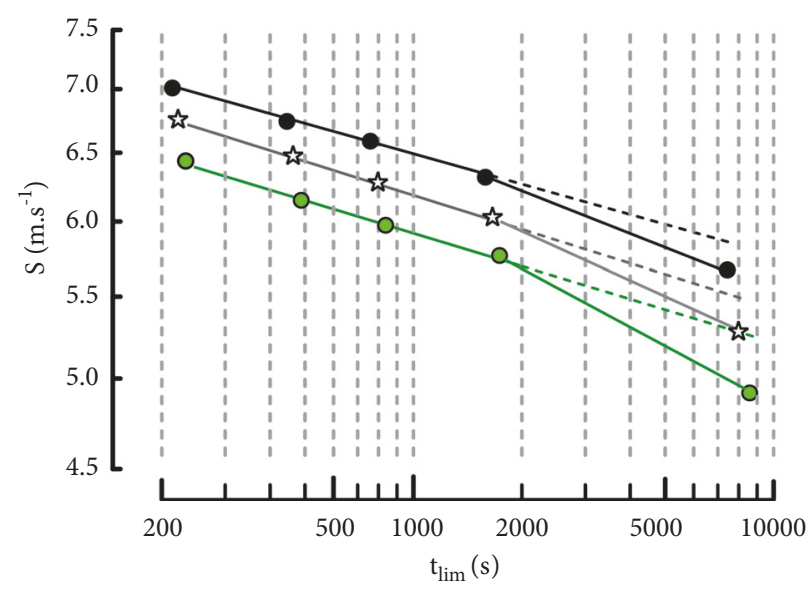

(b)

FIGURE 1: (a) Individual linear relationships (power-law model) with logarithmic scales for running speed and $t_{\text {lim. }}$. The performances by Nurmi and Zatopek were the same for the $1500 \mathrm{~m}$ distance. (b) Extrapolation of the linear relationships (dashed lines) to marathon performances.
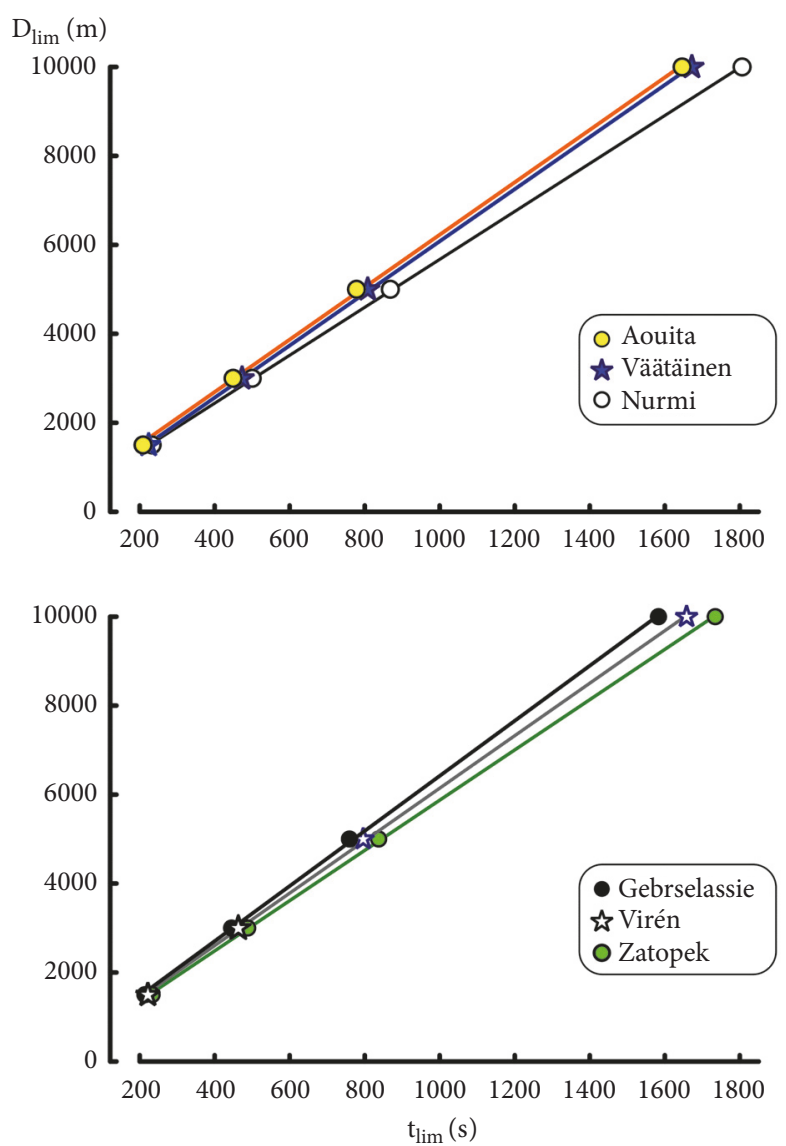

FIGURE 2: Linear relationships between exhaustion time $\left(t_{\text {lim }}\right)$ and distance $\left(D_{\text {lim }}\right)$.

runners. When this model was computed with 3 distances (1500-3000-5000 $\mathrm{m}$ or 3000-5000-10000 m), the correlation coefficients were equal to 1 in all the runners.

The differences in $\mathrm{S}_{\text {Crit }}, \mathrm{S}_{\mathrm{Max}}$, and ADC between the ranges of distances (Table 8$)$ were all significant $(\mathrm{P}=0.031)$.

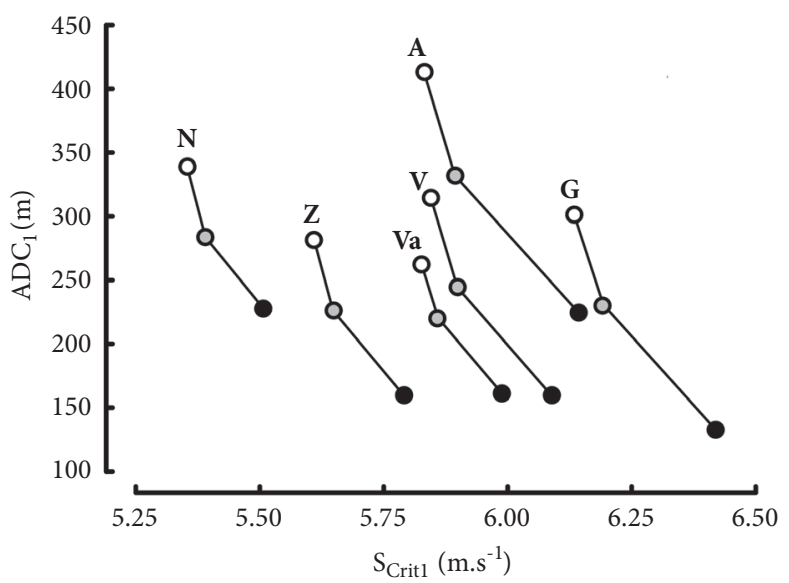

FIGURE 3: Relation between critical speed and Anaerobic Distance Capacity $\left(\mathrm{ADC}_{1}\right)$ for different ranges of distances: 1500 to $5000 \mathrm{~m}$ (black dots), 3000 to $10000 \mathrm{~m}$ (empty circles), and 1500 to $10000 \mathrm{~m}$ (grey dots).

The ratios of estimated to actual speeds are presented in Table 9. In all the runners, the errors were very low $(<0.5 \%)$ for all the distances, from 1500 to $10000 \mathrm{~m}$. However, the values of $\mathrm{S}$ corresponding to a marathon were overestimated in the three runners who participated in this road competition (Figure 6(b)).

4.3. Logarithmic Model Applied to Elite Runners. The values of parameters E and MAS in the logarithmic model depended on the range of running distance (Table 10) but these differences were not significant for MAS between 1500-10000 and 1500-5000 ranges and for E between 1500-5000 range and the two other distance ranges $(\mathrm{P}=0.063)$.

The correlation coefficients were high, $0.995 \pm 0.005$, for the logarithmic model including the four distances from 1500 


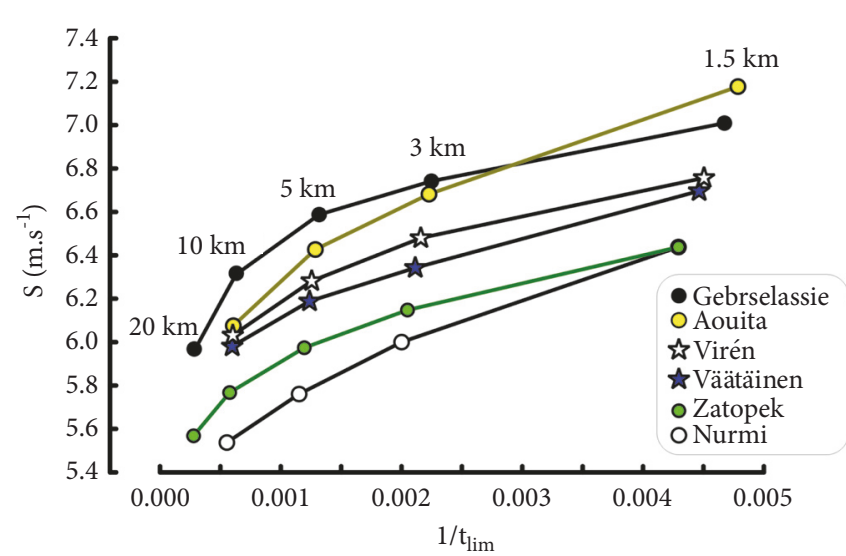

(a)

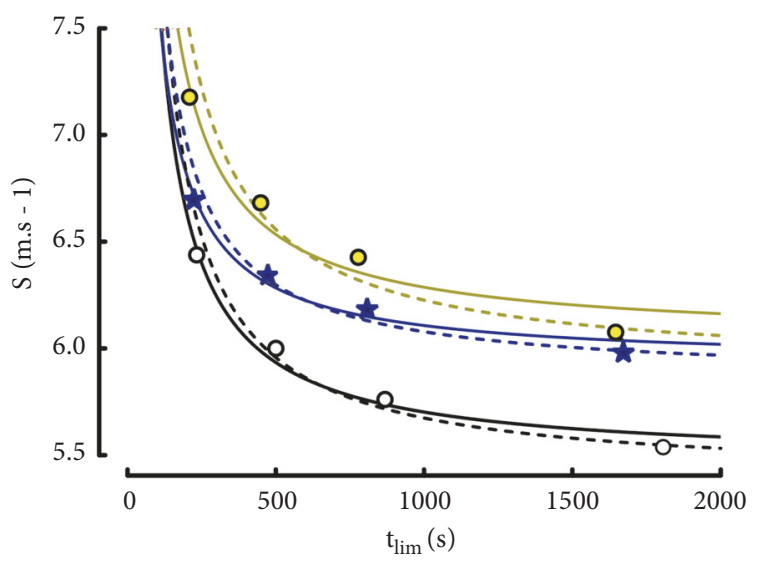

(b)

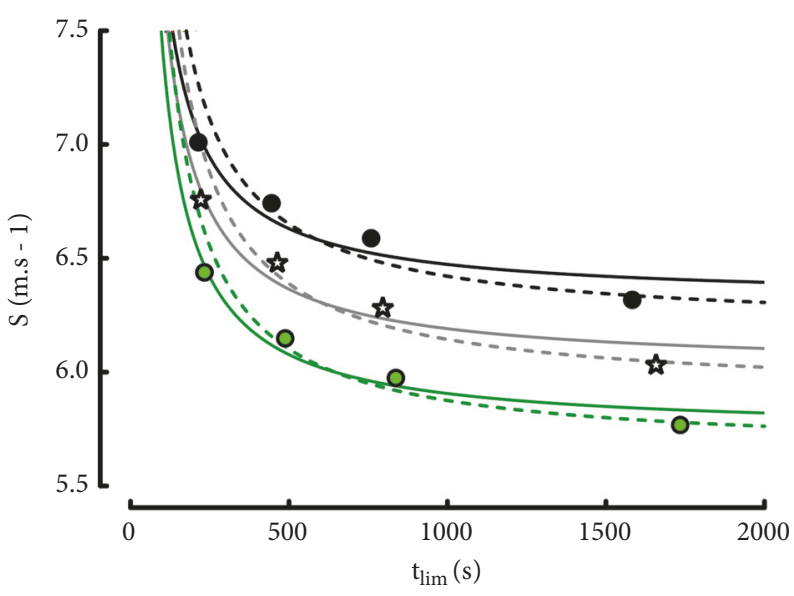

(c)

FIGURE 4: (a) Individual S-1/ $t_{\lim }$ relationships in elite endurance runners. ((b) and (c)) Individual hyperbolic curves corresponding to $\mathrm{S}_{\text {Crit1 }}$ model (dashed curves) and $\mathrm{S}_{\text {Crit2 }}$ model (solid curves).

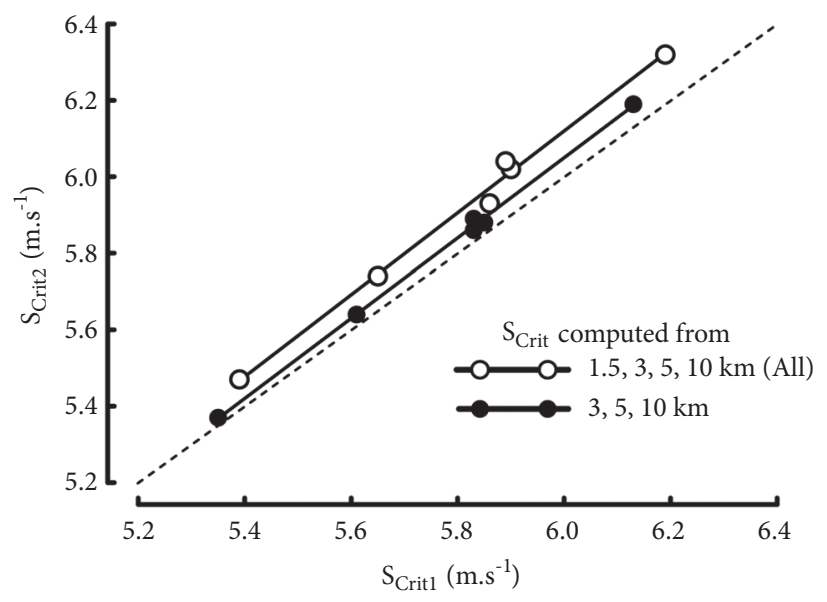

(a)

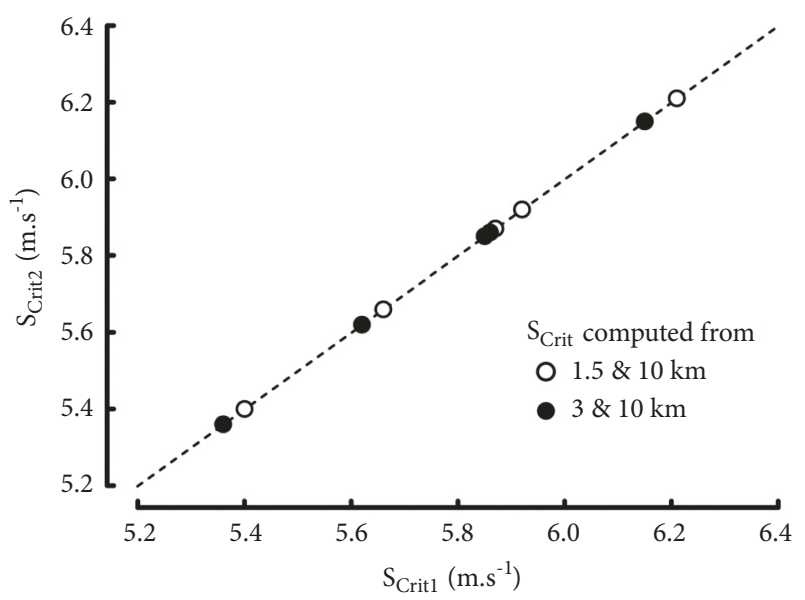

(b)

Figure 5: (a) Relationships between the individual values of $\mathrm{S}_{\text {Crit1 }}$ and $\mathrm{S}_{\text {Crit2 }}$ computed from 3 distances (black dots) or 4 distances (empty circles). (b) Relationships between $\mathrm{S}_{\text {Crit1 }}$ and $\mathrm{S}_{\mathrm{Crit} 2}$ computed from 2 distances, only. 


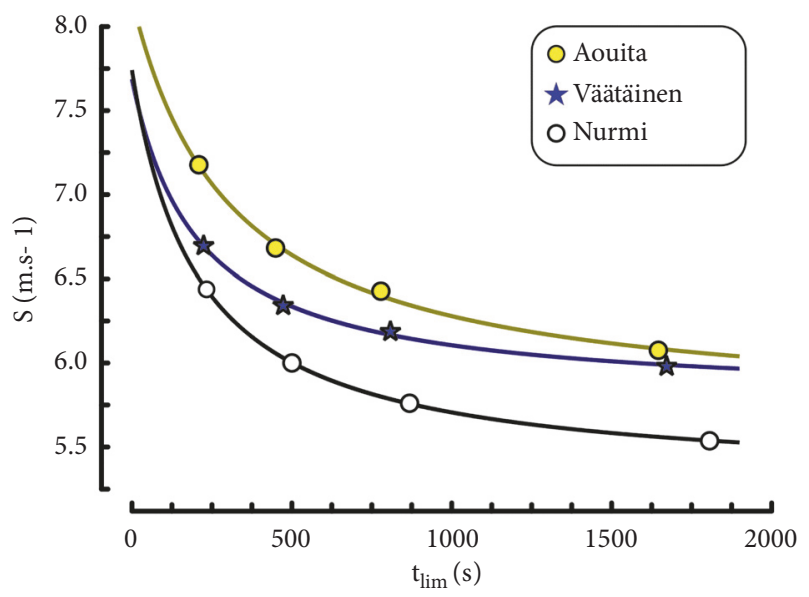

(a)

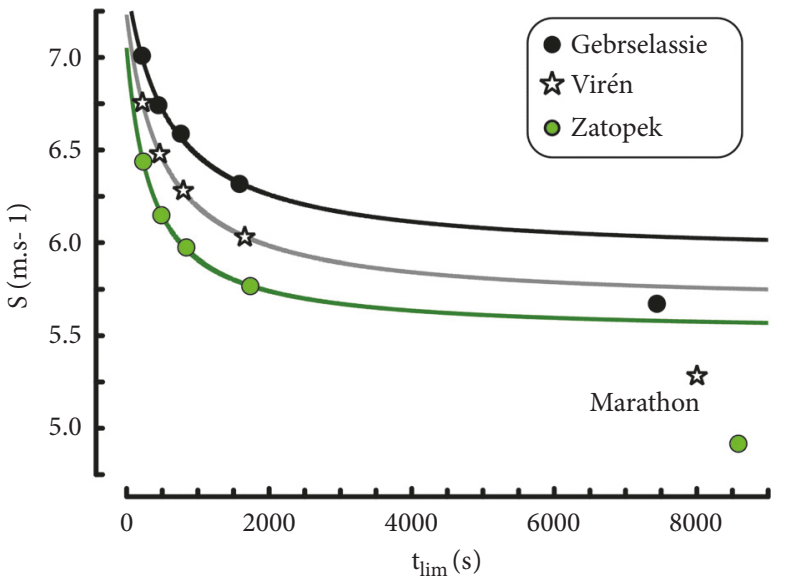

(b)

Figure 6: Relationship between running speed $(S)$ and time $\left(t_{\lim }\right)$ in Morton's model computed from 1500 to $10000 \mathrm{~m}$. (b) The same model in the three subjects who ran the marathon.

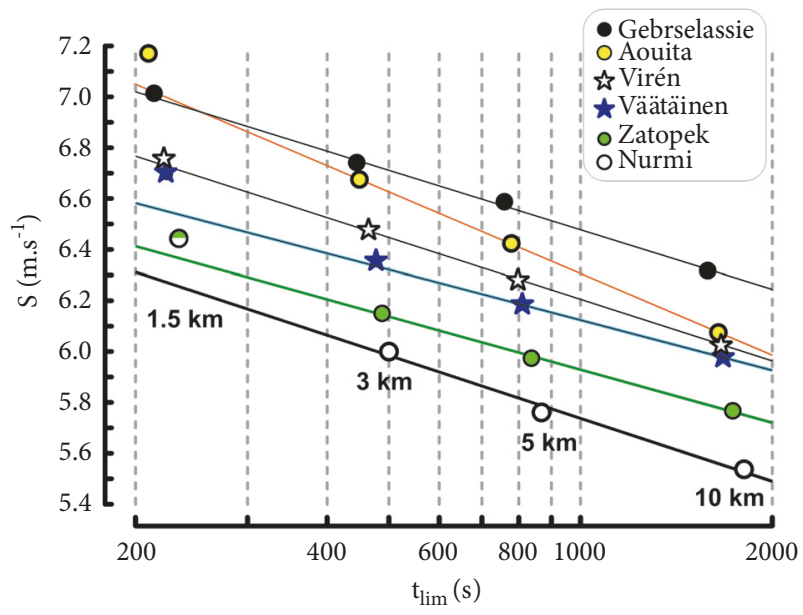

(a)

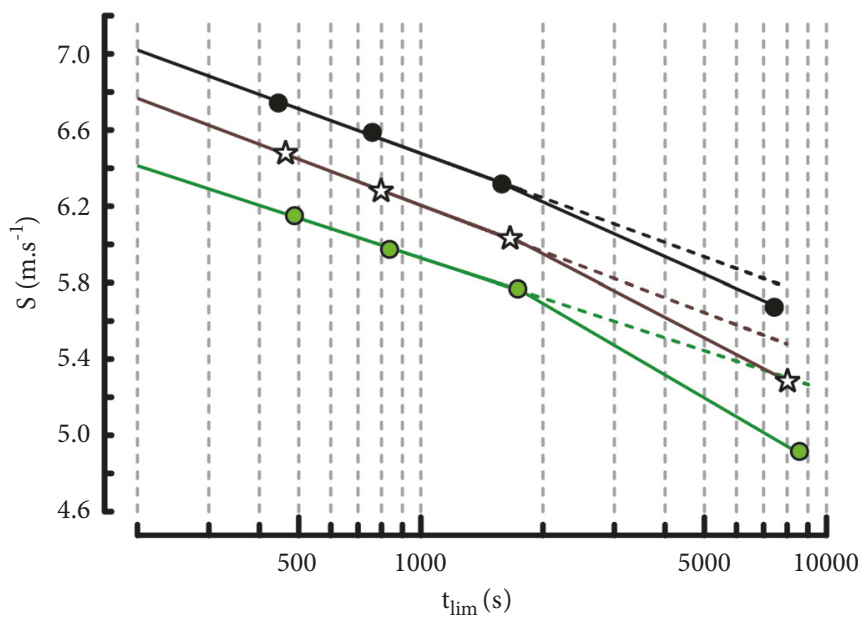

(b)

Figure 7: (a) Individual linear regressions between the logarithms of $t_{\text {lim }}$ and running speeds. The data corresponding to $1.5 \mathrm{~km}$ were not included in the computation of the regressions. The performances by Nurmi and Zatopek were the same for the $1500 \mathrm{~m}$ distance. (b) Extrapolation of the speed-ln $\left(t_{\lim }\right)$ relationships of the 3000-10000 m performances to $t_{\lim }$ corresponding to a marathon (dashed lines). The scale of $t_{\lim }$ is a logarithmic scale.

to $10000 \mathrm{~m}$. The ratios of estimated to actual speeds for the four distances were accurate (Table 11): all the errors were lower than $1 \%$.

When the $1500 \mathrm{~m}$ distance was not included as suggested by Péronnet and Thibault $[7,8]$, the correlation coefficient was higher $(0.999 \pm 0.002)$. The individual running performances between 3000 and $10000 \mathrm{~m}$ were well described by the logarithmic model as shown by the linear regressions between speed and the logarithm of $\mathrm{t}_{\text {lim }}$ (Figure 6(a)).

All the individual $1500 \mathrm{~m}$ performances were above the individual regression lines computed from 3000 to $10000 \mathrm{~m}$ (Figure 6(a)) as in the logarithmic model including the 1500 $\mathrm{m}$ performances (Table 10 ).
On the other hand, marathon performances were under the extrapolation of the lines of regression computed from the 3000-10000 $\mathrm{m}$ track performances (Figures 7(a) and 7(b)).

4.4. Exponential Models Applied to Elite Runners. The relationships between $t_{\lim }$ and $S$ in the exponential model are presented in Figure 8.

As for the other models, the values of parameters $\mathrm{S}_{\infty}, \mathrm{S}_{0}$, and $1 / \tau$ depended on the range of $t_{\lim }-D_{\lim }$ (Table 12).

When computed from 4 distances (Figure 8), the individual regressions were accurate $(r=0.998 \pm 0.0014)$. Similarly, the ratios of estimated to actual speeds for the four distances were highly accurate (Table 13): all the errors were lower 
TABLE 2: Parameters $\mathrm{k}$ and $\mathrm{g}$ according to the ranges of distances used in the computation of the power-law model.

\begin{tabular}{|c|c|c|c|c|c|c|}
\hline & \multicolumn{2}{|c|}{$1500-10000 \mathrm{~m}$} & \multicolumn{2}{|c|}{$1500-5000 \mathrm{~m}$} & \multicolumn{2}{|c|}{$3000-10000 \mathrm{~m}$} \\
\hline & $\mathrm{k}$ & g & $\mathrm{k}$ & g & $\mathrm{k}$ & g \\
\hline Nurmi & 9.55 & 0.926 & 10.2 & 0.915 & 8.80 & 0.938 \\
\hline Zatopek & 8.65 & 0.945 & 8.86 & 0.941 & 8.39 & 0.950 \\
\hline Väätäinen & 8.99 & 0.944 & 9.36 & 0.938 & 8.45 & 0.953 \\
\hline Virén & 9.17 & 0.943 & 9.20 & 0.943 & 9.14 & 0.944 \\
\hline Aouita & 11.0 & 0.920 & 11.3 & 0.915 & 10.5 & 0.927 \\
\hline Gebrselassie & 9.24 & 0.949 & 9.12 & 0.951 & 9.25 & 0.948 \\
\hline Mean & 9.43 & 0.938 & 9.67 & 0.934 & 9.08 & 0.943 \\
\hline SD & 0.81 & 0.012 & 0.90 & 0.015 & 0.76 & 0.010 \\
\hline
\end{tabular}
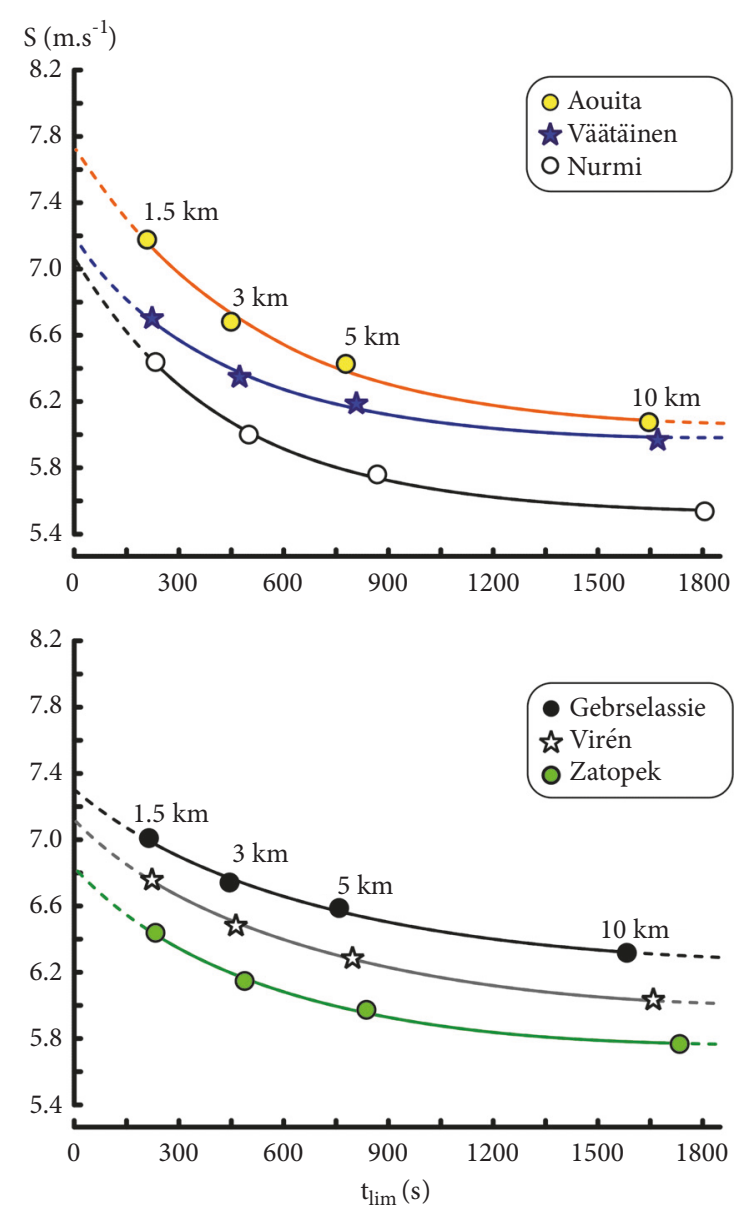

FIGURE 8: Individual relationships between running speed and $\mathrm{t}_{\mathrm{lim}}$ in the Hopkins model computed with 4 distances $(1500-10000 \mathrm{~m})$.

than $0.75 \%$. As expected, the 3-parameter model was more accurate $(r=1)$ for the description of the elite runner performances when it was computed from 3 distances (1.53-5 km or 3-5-10 km), only.

\subsection{Prediction of Running Speeds}

4.5.1. Prediction of Maximal Aerobic Speed. Maximal aerobic speed (MAS) can be estimated by computing the maximal speed corresponding to $7 \mathrm{~min}[7,8]$ from the different models. These estimations (Table 14) were performed by interpolation from the $1500-5000 \mathrm{~m}$ performances.

The effect sizes were small for all the differences $(0.037$ $<$ Cohen's $\mathrm{d}<0.218$ ). The estimations of MAS were almost equal for $\mathrm{S}_{\text {Crit1 }}$ and $\mathrm{S}_{\mathrm{Crit} 2}$ models that were significantly lower than the estimations of all the other models. The differences between all the other models were not significant $(P \geq 0.063)$.

The correlations between the different estimations were highly significant $(r>0.998 ; \mathrm{P}<0.001)$.

4.5.2. Prediction of Maximal Speed during $30 \mathrm{Min}$. The estimations of the maximal running speed during $30 \mathrm{~min}$ done by extrapolation from the $1500-5000 \mathrm{~m}$ performances are compared with the $10000 \mathrm{~m}$ performances $\left(\mathrm{S}_{10000}\right)$ in Table 15. The correlations between the different estimations were highly significant $(\mathrm{r} \geq 0.860$; $\mathrm{P}<0.0025)$. All the different estimations were significantly correlated with $S_{10000}$ $(r \geq 0.989 ; \mathrm{P}<0.001)$. The effect sizes were small for the power-law and logarithmic models (Cohen's $d=0.131$ ) or for the hyperbolic and exponential models (Cohen's $\mathrm{d}=$ 0.033 ) but large for the difference between power-law and exponential models (Cohen's $\mathrm{d}=0.742$ ). The 30-minute running speed estimated from asymptotic models was significantly higher than those estimated from power-law and logarithmic models $(\mathrm{P}=0.031)$. The 30 -min running speed was overestimated by the hyperbolic and exponential models because these estimations were approximately $2.5 \%$ higher than $\mathrm{S}_{10000}(\mathrm{P}=0.031)$ although the individual values of $\mathrm{t}_{\text {lim }}$ corresponding to $10000 \mathrm{~m}$ (Table 2) were lower than 1800 s (from 1583 to 1734 s) except for Nurmi (1806 s). On the contrary, the 30-minute estimated speeds computed with the logarithmic and power-law models were probably close to the actual 30-minute performances since they were slightly lower (0.7 and $1.4 \%$ ) than $S_{10000}$.

4.5.3. Prediction of Maximal Speed during $60 \mathrm{Min}$. The estimations of maximal running speed during $60 \mathrm{~min}$ (Table 16) were done by extrapolation from the 1500-10000 m performances. The effect size between power-law and logarithmic models was small (Cohen's $d=0.073$ ). All the predictions of the 60 -min speeds from the different models were significantly correlated $(\mathrm{r} \geq 0.964 ; \mathrm{P}<0.002)$. However, the 60 minute running speed predicted from the asymptotic models was significantly higher $(\mathrm{P}=0.031)$ than those estimated from 
TABLE 3: Ratios of estimated to actual speeds for the different distances in the power-law model. RMSE = root mean square of the errors between estimated running speed and actual speed.

\begin{tabular}{lccccc}
\hline & 1500 & 3000 & 5000 & 10000 & 0.9899 \\
\hline Nurmi & 0.9909 & 1.0058 & 1.0057 & 0.9954 & 0.00794 \\
Zatopek & 0.9958 & 1.0016 & 1.0005 & 0.9924 & 0.00323 \\
Väätäinen & 0.9919 & 1.0051 & 0.9994 & 0.9963 & 0.00612 \\
Viren & 0.9974 & 0.9974 & 0.9975 & 0.9981 & 0.00290 \\
Aouita & 0.9965 & 1.0077 & 1.0022 & 0.0042 & 0.00309 \\
Gebrselassié & 1.0022 & 1.0039 & $\mathbf{0 . 9 9 6}$ & $\mathbf{0 . 0 0 4 9 5}$ \\
\hline Mean & $\mathbf{0 . 9 9 6}$ & $\mathbf{1 . 0 0 4}$ & $\mathbf{0 . 0 0 1}$ & $\mathbf{0 . 0 0 2 9}$ & $\mathbf{0 . 0 0 2 9 3}$ \\
SD & $\mathbf{0 . 0 0 4 1}$ & & &
\end{tabular}

TABLE 4: Values of $\mathrm{S}_{\text {Crit1 }}$ and ADC of the $\mathrm{S}_{\text {Crit1 }}$ model according to the range of distances. $*: \mathrm{P}=0.031$ for all the differences between the different ranges.

\begin{tabular}{|c|c|c|c|c|c|c|}
\hline & \multicolumn{2}{|c|}{$1500-10000 \mathrm{~m}$} & \multicolumn{2}{|c|}{$1500-5000 \mathrm{~m}$} & \multicolumn{2}{|c|}{$3000-10000 \mathrm{~m}$} \\
\hline & $\mathrm{S}_{\text {Crit1 }}$ & $\mathrm{ADC}_{1}$ & $\mathrm{~S}_{\text {Crit1 }}$ & $\mathrm{ADC}_{1}$ & $\mathrm{~S}_{\text {Crit1 }}$ & $\mathrm{ADC}_{1}$ \\
\hline Nurmi & 5.39 & 284 & 5.51 & 228 & 5.35 & 339 \\
\hline Zatopek & 5.65 & 226 & 5.79 & 160 & 5.61 & 282 \\
\hline Väätäinen & 5.86 & 220 & 5.99 & 161 & 5.83 & 262 \\
\hline Virén & 5.90 & 245 & 6.09 & 160 & 5.85 & 314 \\
\hline Aouita & 5.89 & 332 & 6.14 & 225 & 5.83 & 413 \\
\hline Gebrselassie & 6.19 & 230 & 6.42 & 133 & 6.13 & 301 \\
\hline Mean & $5.81 *$ & $256 *$ & $5.99 *$ & $178 *$ & $5.77 *$ & $319 *$ \\
\hline SD & 0.27 & 44 & 0.31 & 39 & 0.26 & 53 \\
\hline
\end{tabular}

TABLE 5: Ratios of estimated to actual speeds for the different distances in the $S_{\text {Critl }}$ model. $R M S E=$ root mean square of the errors between estimated running speeds and actual speeds.

\begin{tabular}{|c|c|c|c|c|c|}
\hline & 1500 & 3000 & 5000 & 10000 & RMSE \\
\hline Nurmi & 1.032 & 0.992 & 0.992 & 1.002 & 0.0173 \\
\hline Zatopek & 1.033 & 0.994 & 0.990 & 1.002 & 0.0175 \\
\hline Väätäinen & 1.026 & 0.997 & 0.991 & 1.002 & 0.0138 \\
\hline Vir10n & 1.044 & 0.992 & 0.988 & 1.003 & 0.0231 \\
\hline Aouita & 1.056 & 0.993 & 0.983 & 1.004 & 0.0296 \\
\hline Gebrselassié & 1.043 & 0.995 & 0.985 & 1.003 & 0.0231 \\
\hline Mean & 1.039 & 0.994 & 0.988 & 1.003 & 0.021 \\
\hline SD & 0.011 & 0.002 & 0.004 & 0.001 & 0.006 \\
\hline
\end{tabular}

TABLE 6: Values of $\mathrm{S}_{\mathrm{Crit} 2}$ and $\mathrm{ADC}_{2}$ according to the range of distances. $*: \mathrm{P}=0.031$ for all the differences between the different ranges.

\begin{tabular}{|c|c|c|c|c|c|c|}
\hline & \multicolumn{2}{|c|}{$1500-10000 \mathrm{~m}$} & \multicolumn{2}{|c|}{$1500-5000 \mathrm{~m}$} & \multicolumn{2}{|c|}{$3000-10000 \mathrm{~m}$} \\
\hline & $\mathrm{S}_{\text {Crit2 }}$ & $\mathrm{ADC}_{2}$ & $\mathrm{~S}_{\text {Crit2 }}$ & $\mathrm{ADC}_{2}$ & $\mathrm{~S}_{\text {Crit2 }}$ & $\mathrm{ADC}_{2}$ \\
\hline Nurmi & 5.47 & 233 & 5.54 & 211 & 5.37 & 318 \\
\hline Zatopek & 5.74 & 171 & 5.82 & 146 & 5.64 & 257 \\
\hline Väätäinen & 5.93 & 176 & 6.00 & 156 & 5.86 & 235 \\
\hline Virén & 6.02 & 174 & 6.14 & 141 & 5.88 & 283 \\
\hline Aouita & 6.04 & 248 & 6.18 & 210 & 5.89 & 368 \\
\hline Gebrselassie & 6.32 & 157 & 6.44 & 123 & 6.19 & 257 \\
\hline Mean & $5.92 *$ & $193 *$ & $6.02 *$ & $165 *$ & $5.81 *$ & $286 *$ \\
\hline SD & 0.29 & 38 & 0.31 & 37 & 0.28 & 49 \\
\hline
\end{tabular}


TABLE 7: Ratios of estimated to actual speeds for the different distances in the $\mathrm{S}_{\text {Crit2 }}$ model. RMSE $=$ root mean square of the errors between estimated running speed and actual speed.

\begin{tabular}{lccccc}
\hline & 1500 & 3000 & 5000 & 10000 & 1.011 \\
\hline Nurmi & 1.005 & 0.989 & 0.996 & 1.012 & 0.00834 \\
Zatopek & 1.005 & 0.990 & 0.994 & 1.009 & 0.00855 \\
Väätäinen & 1.003 & 0.994 & 0.994 & 1.015 & 0.00659 \\
Viren & 1.006 & 0.987 & 0.993 & 0.0112 \\
Aouita & 1.007 & 0.986 & 0.989 & 1.019 & 1.016 \\
Gebrselassié & 1.006 & 0.989 & $\mathbf{0 . 9 9 0}$ & $\mathbf{1 . 0 1 4}$ & 0.0110 \\
\hline Mean & $\mathbf{1 . 0 0 5}$ & $\mathbf{0 . 9 8 9}$ & $\mathbf{0 . 0 0 3 5}$ & $\mathbf{0 . 0 0 9 8 1}$ \\
SD & $\mathbf{0 . 0 0 1 3}$ & $\mathbf{0 . 0 0 2 7}$ & $\mathbf{0 . 0 0 2 5}$ & $\mathbf{0 . 0 0 2 4 1}$ \\
\hline
\end{tabular}

TABLE 8: Values of $\mathrm{S}_{\mathrm{Crit} 3}, \mathrm{~S}_{\mathrm{Max}}$ and ADC of Morton's model according to the range of distances. $*: \mathrm{P}=0.031$ for all the differences between the different ranges.

\begin{tabular}{|c|c|c|c|c|c|c|c|c|c|}
\hline & \multicolumn{3}{|c|}{$1500-10000 \mathrm{~m}$} & \multicolumn{3}{|c|}{$1500-5000 \mathrm{~m}$} & \multicolumn{3}{|c|}{$3000-10000 \mathrm{~m}$} \\
\hline & $\mathrm{S}_{\text {Crit3 }}$ & $S_{\text {Max }}$ & $\mathrm{ADC}$ & $\mathrm{S}_{\text {Crit3 }}$ & $\mathrm{S}_{\mathrm{Max}}$ & $\mathrm{ADC}$ & $\mathrm{S}_{\text {Crit3 }}$ & $\mathrm{S}_{\mathrm{Max}}$ & $\mathrm{ADC}$ \\
\hline Nurmi & 5.29 & 7.74 & 504 & 5.31 & 7.85 & 470 & 5.27 & 7.45 & 549 \\
\hline Zatopek & 5.51 & 7.05 & 539 & 5.61 & 7.25 & 388 & 5.44 & 6.74 & 760 \\
\hline Vaatainen & 5.78 & 7.69 & 393 & 5.94 & 9.70 & 211 & 5.59 & 6.77 & 982 \\
\hline Viren & 5.67 & 7.23 & 793 & 5.77 & 7.31 & 605 & 5.60 & 7.08 & 995 \\
\hline Aouita & 5.69 & 8.16 & 772 & 5.98 & 9.07 & 410 & 5.41 & 7.34 & 1666 \\
\hline Gebrselassié & 5.92 & 7.40 & 868 & 6.28 & 7.85 & 292 & 5.46 & 7.05 & 2961 \\
\hline Mean & $5.64 *$ & $7.55 *$ & $645 *$ & $5.82 *$ & $8.17 *$ & $396 *$ & $5.46 *$ & $7.07 *$ & $1319 *$ \\
\hline SD & 0.22 & 0.40 & 193 & 0.33 & 0.99 & 137 & 0.12 & 0.29 & 888 \\
\hline
\end{tabular}

TABLE 9: Ratios of estimated to actual speeds for the different distances in Morton's model. RMSE = root mean square of the errors between estimated running speed and actual speed.

\begin{tabular}{|c|c|c|c|c|c|}
\hline & 1500 & 3000 & 5000 & 10000 & RMSE \\
\hline Nurmi & 1.0000 & 1.0004 & 0.9995 & 1.0003 & 0.00036 \\
\hline Zatopek & 0.9997 & 1.0012 & 0.9985 & 1.0005 & 0.00100 \\
\hline Väätäinen & 0,9996 & 1.0027 & 0.9965 & 1.0014 & 0.00236 \\
\hline Viren & 0.9997 & 1.0008 & 0.9990 & 1.0003 & 0.00069 \\
\hline Aouita & 0.9993 & 1.0038 & 0.9953 & 1.0017 & 0.00315 \\
\hline Gebrselassié & 0.9992 & 1.0033 & 0.9968 & 1.0010 & 0.00241 \\
\hline Mean & 0.9996 & 1.0020 & 0.9976 & 1.0009 & 0.0017 \\
\hline SD & 0.0003 & 0.0014 & 0.0016 & 0.0006 & 0.0011 \\
\hline
\end{tabular}

TABLE 10: Values of MAS and $\mathrm{E}$ in the logarithmic model according to the range of distances. ${ }^{\mathrm{a}}: \mathrm{P}=0.031$ between $1500-10000$ and $3000-10000$ $\mathrm{m} ;{ }^{\mathrm{b}}: \mathrm{P}=0.031$ between $1500-5000$ and $3000-10000 \mathrm{~m}$.

\begin{tabular}{|c|c|c|c|c|c|c|}
\hline & \multicolumn{2}{|c|}{$1500-10000 \mathrm{~m}$} & \multicolumn{2}{|c|}{$1500-5000 \mathrm{~m}$} & \multicolumn{2}{|c|}{$3000-10000 \mathrm{~m}$} \\
\hline & MAS & $\mathrm{E}$ & MAS & $\mathrm{E}$ & MAS & $\mathrm{E}$ \\
\hline Nurmi & 6.13 & 7.18 & 6.12 & 8.48 & 6.05 & 5.90 \\
\hline Zatopek & 6.22 & 5.35 & 6.22 & 5.87 & 6.19 & 4.83 \\
\hline Väätäinen & 6.44 & 5.47 & 6.43 & 6.24 & 6.38 & 4.49 \\
\hline Virén & 6.52 & 5.54 & 6.52 & 5.72 & 6.51 & 5.39 \\
\hline Aouita & 6.77 & 7.82 & 6.76 & 8.52 & 6.71 & 6.96 \\
\hline Gebrselassie & 6.78 & 5.05 & 6.78 & 4.94 & 6.77 & 4,98 \\
\hline Mean & 6.48 & 6.07 & 6.47 & 6.63 & $6.43^{a, b}$ & $5.42^{\mathrm{a}}$ \\
\hline SD & 0.27 & 1.14 & 0.27 & 1.51 & 0.29 & 0.90 \\
\hline
\end{tabular}


TABLE 11: Ratios of estimated to actual speeds for the different distances in the logarithmic model. RMSE = root mean square of the errors between estimated running speeds and actual speeds.

\begin{tabular}{lccccc}
\hline & 1500 & 3000 & 5000 & 10000 & 0.990 \\
\hline Nurmi & 0.992 & 1.009 & 1.009 & 0.996 & 0.00916 \\
Zatopek & 0.997 & 1.004 & 1.003 & 0.994 & 0.00352 \\
Väätäinen & 0.993 & 1.008 & 1.002 & 0.998 & 0.00622 \\
Viren & 0.999 & 1.000 & 1.001 & 0.995 & 1.001 \\
Aouita & 0.994 & 1.008 & 0.003 & 0.00594 \\
Gebrselassié & 0.999 & 1.002 & $\mathbf{0 . 9 9 6}$ & 0.00167 \\
\hline Mean & $\mathbf{0 . 9 9 6}$ & $\mathbf{1 . 0 0 5}$ & $\mathbf{0 . 0 0 3 7}$ & $\mathbf{0 . 0 0 4 6 0}$ \\
SD & $\mathbf{0 . 0 0 3 1}$ & $\mathbf{0 . 0 0 3 7}$ & $\mathbf{0 . 0 0 3 8}$ & $\mathbf{0 . 0 0 3 0 2}$ \\
\hline
\end{tabular}

TABLE 12: Values of $\mathrm{S}_{\infty}, \mathrm{S}_{0}$ and $1 / \tau$ of the exponential model according to the range of distances. $*: \mathrm{P}=0.031$ for all the differences between the different ranges.

\begin{tabular}{lccccccccc}
\hline & \multicolumn{3}{c}{$1500-10000 \mathrm{~m}$} & \multicolumn{3}{c}{$1500-5000 \mathrm{~m}$} & \multicolumn{3}{c}{$3000-10000 \mathrm{~m}$} \\
& $\mathrm{~S}_{\infty}$ & $\mathrm{S}_{0}$ & $1 / \tau$ & $\mathrm{S}_{\infty}$ & $\mathrm{S}_{0}$ & $1 / \tau$ & $\mathrm{S}_{\infty}$ & $\mathrm{S}_{0}$ & $1 / \tau$ \\
\hline Nurmi & 5.52 & 7.06 & 0.00224 & 5.64 & 7.24 & 0.00298 & 5.48 & 6.68 & 0.00167 \\
Zatopek & 5.73 & 6.81 & 0.00187 & 5.87 & 6.96 & 0.00280 & 5.68 & 6.57 & 0.00132 \\
Vaatainen & 5.97 & 7.17 & 0.00228 & 6.13 & 7.50 & 0.00397 & 5.86 & 6.69 & 0.00115 \\
Virén & 5.96 & 7.10 & 0.00163 & 6.11 & 7.20 & 0.00234 & 5.91 & 6.94 & 0.00127 \\
Aouita & 6.03 & 7.76 & 0.00202 & 6.31 & 8.13 & 0.00354 & 5.87 & 7.23 & 0.00114 \\
Gebreselassie & 6.23 & 7.29 & 0.00151 & 6.50 & 7.52 & 0.00323 & 5.99 & 7.03 & 0.00073 \\
\hline Means & $\mathbf{5 . 9 1 *}$ & $\mathbf{7 . 2 0} *$ & $\mathbf{0 . 0 0 1 9 3 *}$ & $\mathbf{6 . 0 9 *}$ & $\mathbf{7 . 4 3} *$ & $\mathbf{0 . 0 0 3 1 4 *}$ & $\mathbf{5 . 8 0} *$ & $\mathbf{6 . 8 6} *$ & $\mathbf{0 . 0 0 1 2 1} *$ \\
SD & $\mathbf{0 . 2 5}$ & $\mathbf{0 . 3 2}$ & $\mathbf{0 . 0 0 0 3 2}$ & $\mathbf{0 . 3 1}$ & $\mathbf{0 . 4 0}$ & $\mathbf{0 . 0 0 0 5 7}$ & $\mathbf{0 . 1 9}$ & $\mathbf{0 . 2 5}$ & $\mathbf{0 . 0 0 0 3 1}$ \\
\hline
\end{tabular}

TABLE 13: Ratios of the estimated to actual speeds in the different distances for the exponential model. RMSE = root mean square of the errors between estimated running speeds and actual speeds.

\begin{tabular}{lccccc}
\hline & 1500 & 3000 & 5000 & 10000 & 1.002 \\
\hline Nurmi & 0.999 & 1.004 & 0.996 & 1.001 & 0.00293 \\
Zatopek & 0.999 & 1.003 & 0.997 & 1.002 & 0.00227 \\
Väätäinen & 0.998 & 1.005 & 0.994 & 1.001 & 0.00405 \\
Viren & 0.999 & 1.002 & 0.998 & 0.00162 \\
Aouita & 0.998 & 1.007 & 0.993 & 0.002 & 0.00530 \\
Gebrselassié & 0.998 & 1.005 & $\mathbf{0 . 9 9 6}$ & $\mathbf{1 . 0 0 1}$ & 0.00309 \\
\hline Mean & $\mathbf{0 . 9 9 9}$ & $\mathbf{1 . 0 0 4}$ & $\mathbf{0 . 0 0 1 8}$ & $\mathbf{0 . 0 0 0 6}$ & $\mathbf{0 . 0 0 3 2 1}$ \\
SD & $\mathbf{0 . 0 0 0 5}$ & $\mathbf{0 . 0 0 1 8}$ & & $\mathbf{0 . 0 0 1 3 1}$ \\
\hline
\end{tabular}

TABLE 14: Estimation of maximal running speed $\left(\mathrm{m} . \mathrm{s}^{-1}\right)$ corresponding to $420 \mathrm{~s}$ computed from the different models. $*: \mathrm{P}=0.031$ for the differences with Morton's model, exponential, logarithmic and power-law models.

\begin{tabular}{|c|c|c|c|c|c|c|}
\hline & SCrit1 & SCrit2 & Morton & Exponential & $\log$ & Power \\
\hline Nurmi & 6.0491 & 6.0454 & 6.09 & 6.10 & 6.12 & 6.11 \\
\hline Zatopek & 6.1714 & 6.1669 & 6.20 & 6.21 & 6.22 & 6.20 \\
\hline Väätäinen & 6.3716 & 6.3737 & 6.39 & 6.39 & 6.43 & 6.41 \\
\hline Virén & 6.4693 & 6.4690 & 6.52 & 6.52 & 6.52 & 6.53 \\
\hline Aouita & 6.6776 & 6.6812 & 6.72 & 6.72 & 6.76 & 6.75 \\
\hline Gebrselassie & 6.7348 & 6.7349 & 6.76 & 6.76 & 6.78 & 6.79 \\
\hline Means & $6.412 *$ & $6.412 *$ & 6.45 & 6.45 & 6.47 & 6.47 \\
\hline SD & 0.272 & 0.274 & 0.27 & 0.27 & 0.27 & 0.28 \\
\hline
\end{tabular}


TABLE 15: Maximal running speed $\left(\mathrm{m} . \mathrm{s}^{-1}\right)$ during $30 \mathrm{~min}$, computed from the different models. $\mathrm{S}_{10000}:$ running speed over $10000 \mathrm{~m} ; *: \mathrm{P}=$ 0.031 for the differences with logarithmic and power-law models. ${ }^{1}: \mathrm{P}=0.031$ for the differences with $\mathrm{S}_{\text {Critl }}$ model. ${ }^{3}: \mathrm{P}=0.031$ for the differences with Morton's model. ${ }^{\mathrm{S}}$ : $\mathrm{P}=0.031$ for the differences with $\mathrm{S}_{10000}$.

\begin{tabular}{|c|c|c|c|c|c|c|c|}
\hline & $\log$ & Power & Morton & $\mathrm{S}_{\text {Crit1 }}$ & Exp & $\mathrm{S}_{\text {Crit2 }}$ & S10000 \\
\hline Nurmi & 5.36 & 5.40 & 5.55 & 5.63 & 5.65 & 5.66 & 5.54 \\
\hline Zatopek & 5.69 & 5.69 & 5.80 & 5.88 & 5.88 & 5.90 & 5.77 \\
\hline Väätäinen & 5.84 & 5.85 & 6.06 & 6.08 & 6.13 & 6.09 & 5.98 \\
\hline Virén & 5.98 & 6.01 & 6.05 & 6.18 & 6.13 & 6.21 & 6.03 \\
\hline Aouita & 5.92 & 5.96 & 6.19 & 6.27 & 6.31 & 6.30 & 6.07 \\
\hline Gebrselassie & 6.29 & 6.32 & 6.43 & 6.49 & 6.50 & 6.52 & 6.32 \\
\hline Mean & $5.85^{\mathrm{S}}$ & 5.87 & $6.01 *$, & $\mathbf{6 . 0 9} *^{, 3, \mathrm{~S}}$ & $6.10 *^{3, S}$ & $6.11 *^{1,3, S}$ & 5.95 \\
\hline SD & 0.31 & 0.31 & 0.30 & 0.30 & 0.31 & 0.30 & 0.27 \\
\hline
\end{tabular}

TABLE 16: Maximal running speed $\left(\mathrm{m} . \mathrm{s}^{-1}\right)$ during 60 min computed from the different models. $*: \mathrm{P}=0.031$ for the differences with logarithmic model. ${ }^{\mathrm{P}}: \mathrm{P}=0.031$ for the differences with power-law model. ${ }^{1}: \mathrm{P}=0.031$ for the differences with $\mathrm{S}_{\text {Critl }}$ model. ${ }^{3}: \mathrm{P}=0.031$ for the differences with Morton's model. ${ }^{\mathrm{E}}: \mathrm{P}=0.031$ for the differences with exponential model.

\begin{tabular}{|c|c|c|c|c|c|c|}
\hline & $\log$ & Power & Morton & $\mathrm{S}_{\text {Crit1 }}$ & Exp & $\mathrm{S}_{\text {Crit2 }}$ \\
\hline Nurmi & 5.18 & 5.21 & 5.42 & 5.47 & 5.52 & 5.53 \\
\hline Zatopek & 5.50 & 5.52 & 5.65 & 5.71 & 5.73 & 5.78 \\
\hline Väätäinen & 5.68 & 5.69 & 5.88 & 5.92 & 5.96 & 5.98 \\
\hline Virén & 5.74 & 5.75 & 5.86 & 5.97 & 5.95 & 6.07 \\
\hline Aouita & 5.63 & 5.69 & 5.89 & 5.99 & 6.02 & 6.11 \\
\hline Gebrselassie & 6.04 & 6.08 & 6.13 & 6.25 & 6.22 & 6.36 \\
\hline Mean & 5.63 & $5.66 *$ & $5.81 *^{, P}$ & $5.88 *{ }^{\mathrm{P}, 3}$ & $5.91 *^{, P, 3}$ & $5.97 *{ }^{, P, 1,3, E}$ \\
\hline SD & 0.28 & 0.29 & 0.24 & 0.27 & 0.25 & 0.29 \\
\hline
\end{tabular}

power-law and logarithmic models. Moreover, the prediction of the 60-minute running speed from the power-law model was higher than that from the logarithmic model $(\mathrm{P}=$ 0.031). It is possible that the 60-minute running speeds estimated from power-law and logarithmic models were slightly overestimated because the world record on one hour by Gebrselassie was about $2.5 \%$ slower $\left(5.913 \mathrm{~m} . \mathrm{s}^{-1}\right.$ instead of $6.04 \mathrm{~m} . \mathrm{s}^{-1}$ for the logarithmic model and $6.08 \mathrm{~m} . \mathrm{s}^{-1}$ for the power-law model). On the other hand, the record by Zatopek on $20 \mathrm{~km}$ (3591 s; $\left.5.57 \mathrm{~m} . \mathrm{s}^{-1}\right)$ was slightly faster than the 60 minute running speeds $S$ estimated from the power-law (5.52 $\left.\mathrm{m} . \mathrm{s}^{-1}\right)$ and logarithmic $\left(5.50 \mathrm{~m} . \mathrm{s}^{-1}\right)$ models.

4.5.4. Prediction of Marathon Performances. The overestimations of the marathon running speed (Figure 9) by the different models were similar in the 3 runners. The predictions of marathon running speeds from the logarithmic model (red curves in Figure 9) were 5.216 m.s ${ }^{-1}$ for Zatopek, 5.457 $\mathrm{m} . \mathrm{s}^{-1}$ for Viren, and $5.792 \mathrm{~m} . \mathrm{s}^{-1}$ for Gebrselassié, which corresponded to overestimations equal to $6.1 \%, 3.4 \%$, and $2.1 \%$, respectively. The overestimations by the power-law model (blue curves in Figure 9) were slightly higher than those of the logarithmic model in the 3 runners.

On the other hand, the overestimations were more important with the four asymptotic models (hyperbolic models and exponential model). These overestimations by the asymptotic models were similar for the 3 runners who ran the marathon distance. The large overestimations were similar for the
TABLE 17: Average values of the 6 runners Roots Mean Square Errors (RMSE) for the different models.

\begin{tabular}{lc}
\hline & RMSE \\
\hline Morton's model & $0.00166 \pm 0.00113$ \\
Exponential model & $0.00321 \pm 0.00131$ \\
Power-law model & $0.00463 \pm 0.00203$ \\
Logarithmic model & $0.00464 \pm 0.00302$ \\
$\mathrm{~S}_{\text {Crit2 }}$ model & $0.00981 \pm 0.00241$ \\
$\mathrm{~S}_{\text {Crit1 }}$ model & $0.0207 \pm 0.00566$ \\
\hline
\end{tabular}

$\mathrm{S}_{\text {Crit1 }}$ and $\mathrm{S}_{\text {Crit2 }}$ models (orange curves) and exponential model (black curve). In the 3 marathon runners, the lowest overestimations by an asymptotic model corresponded to Morton's model (green curves).

4.6. Comparison of the Accuracies of the Different Models. For the modelling of the four distances (from 1500 to 10000 $\mathrm{m})$, the lowest mean values of the RMSE of the six runners corresponded to Morton's model (Table 17).

The statistical significance values of the differences of the squared errors between the different models for the four distances and six runners $(\mathrm{n}=24)$ are presented in Table 18. The accuracy of Morton's model was significantly better than those of all the other models. The accuracies of the powerlaw and logarithmic models were not statistically different. The accuracies of $S_{\text {Crit1 }}$ and $S_{\text {Crit2 }}$ models were not statistically 
TABLE 18: Values of paired Student't test (underlined) or Wilcoxon signed rank test for the difference in squared errors between the running models.

\begin{tabular}{|c|c|c|c|c|c|c|}
\hline & Power law & $\mathrm{S}_{\text {Crit1 }}$ & $\mathrm{S}_{\text {Crit2 }}$ & Morton & Logarithmic & Exponential \\
\hline Power law & $\mathrm{X}$ & & & & & \\
\hline$S_{\text {Crit1 }}$ & 0.003 & $\mathrm{X}$ & & & & \\
\hline$S_{\text {Crit2 }}$ & $\leq 0.001$ & 0.484 & $\mathrm{X}$ & & & \\
\hline Morton & 0.001 & 0.001 & $\leq 0.001$ & $\mathrm{X}$ & & \\
\hline Logarithmic & 0.830 & $<0.001$ & $\leq 0.001$ & 0.005 & $\mathrm{X}$ & \\
\hline Exponential & 0.061 & $<0.001$ & $\leq 0.001$ & $<0.001$ & 0.017 & $\mathrm{X}$ \\
\hline
\end{tabular}

TABLE 19: Correlation coefficients of the linear regressions between the different endurance indices. $*: \mathrm{P}=0.05 ; * * *: \mathrm{P}<0.001$.

\begin{tabular}{|c|c|c|c|c|c|c|}
\hline & $\mathrm{S}_{\text {Crit1 }}$ & $\mathrm{S}_{\text {Crit3 }}$ & $\mathrm{g}$ & $\mathrm{E}$ & $\mathrm{S}_{\text {Crit1 } 1} / \mathrm{S}_{420}$ & $\mathrm{~S}_{\text {Crit } 3} / \mathrm{S}_{420}$ \\
\hline$S_{\text {Crit1 }}$ & $\mathrm{X}$ & & & & & \\
\hline $\mathrm{S}_{\text {Crit3 }}$ & $0.965 * *$ & $\mathrm{X}$ & & & & \\
\hline $\mathrm{g}$ & 0.551 & 0.513 & $\mathrm{X}$ & & & \\
\hline $\mathrm{E}$ & 0.538 & 0.499 & $0.999 * * *$ & $\mathrm{X}$ & & \\
\hline$S_{\infty}$ & $0.985 * * *$ & $0.984 * * *$ & 0.435 & 0.422 & & \\
\hline $\mathrm{S}_{\text {Crit } 1} / S_{420}$ & & & $0.976 * * *$ & $0.973 * * *$ & $\mathrm{X}$ & \\
\hline $\mathrm{S}_{\mathrm{Crit} 3} / \mathrm{S}_{420}$ & & & 0.683 & 0.676 & 0.775 & $\mathrm{X}$ \\
\hline $\mathrm{S}_{\infty} / \mathrm{S}_{420}$ & & & 0.720 & 0.711 & $0.824 *$ & $0.991 * * *$ \\
\hline
\end{tabular}

different but were significantly lower than those of all the other models.

\subsection{Correlations between the Parameters of the Different Models}

4.7.1. Correlations of the Endurance Indices. In Table 19, the comparisons of the endurance indices concern the indices computed with the running performances from 1500 to $5000 \mathrm{~m}$ that corresponded to the usual range of $\mathrm{t}_{\lim }$ (3.5 to $15 \mathrm{~min}$ ) in the studies on the modelling of the individual performances in nonelite runners. The correlations between the dimensionless indices ( $\mathrm{E}$ and $\mathrm{g}$ ) and either $\mathrm{S}_{\mathrm{Crit1}}$ or $\mathrm{S}_{\text {Crit3 }}$ or $\mathrm{S}_{\infty}$ were not significant. In contrast, $\mathrm{S}_{\text {Crit } 1}, \mathrm{~S}_{\mathrm{Crit} 3}$, and $\mathrm{S}_{\infty}$ were significantly correlated.

When $\mathrm{S}_{\text {Critl }}$ was normalised to an estimate of maximal aerobic speed $\left(\mathrm{S}_{420}\right)$ computed from the same model (Table 14), its correlations with the dimensionless indices $\mathrm{g}$ and E became significant (Table 19). After normalisation to $\mathrm{S}_{420}$ computed from the same model (Table 14), the correlation coefficients between $S_{\text {Crit3 }}$ or $S_{\infty}$ and the dimensionless indices ( $\mathrm{E}$ and $\mathrm{g}$ ) increased but were not significant.

4.7.2. Correlations between $S_{\text {Max }}, S_{0}$, and $k$. When $\mathrm{k}, \mathrm{S}_{\mathrm{Max}}$, and $\mathrm{S}_{0}$ were computed from the performances in the 4 distances (from 1500 to $10000 \mathrm{~m}$, Tables 2, 8, and 12), these parameters were significantly correlated $(\mathrm{P} \leq 0.044)$ :

$$
\begin{array}{rl}
\mathrm{S}_{\max }=0.0617+1.040 \mathrm{~S}_{0} & \mathrm{r}=0.824 \\
\mathrm{k} & =-3.923+1.770 \mathrm{~S}_{\max } \quad \mathrm{r}=0.862 \\
\mathrm{k} & =-7.55+2.357 \mathrm{~S}_{0} \quad \mathrm{r}=0.910
\end{array}
$$

Parameter $\mathrm{S}_{\text {Max }}$ was significantly higher than $\mathrm{S}_{0}(\mathrm{P}=0.031)$. Parameter $\mathrm{k}$ was significantly higher than $\mathrm{S}_{\mathrm{Max}}$ and $\mathrm{S}_{0}(\mathrm{P}=$ 0.031).

When $\mathrm{S}_{\mathrm{Max}}, \mathrm{S}_{0}$, and $\mathrm{k}$ were computed from 3 distance performances (1500-3000-5000) their values were significantly higher $(\mathrm{P}=0.031)$ for $\mathrm{S}_{\mathrm{Max}}$ and $\mathrm{S}_{0}$ but there was no significant correlation between $S_{\text {Max }}, S_{0}$, and $k(r \leq 0.788 ; P \geq 0.063)$.

\section{Discussion}

Interestingly, for a given distance and a given model, the ratios of estimated to actual speeds were similar for the six runners (Tables 3, 5, 7, 9, 11, and 13). Indeed, for a given distance and a given model, the ratios of estimated to actual speed were not spread around 1 but either all the ratios were higher than 1 or all were lower (except several runners in the power-law model and one in the logarithmic model). Therefore, the modelling of the running performances was probably similar for the six elite runners although they ran in different conditions and they were probably trained according to different programmes. However, it cannot be excluded that there were submaximal performances in some runners. Indeed, the models would be similar if the ratios of submaximal speeds to maximal speeds are the same for each distance in a runner.

5.1. Effects of the Range of $t_{\text {lim }}$. In the present study, there were significant differences in the parameters computed from the 3 different ranges of distances for the 3 hyperbolic models and the exponential model.

The effect of the range of $t_{\lim }$ on a parameter is the most important for parameter ADC computed from the 3 

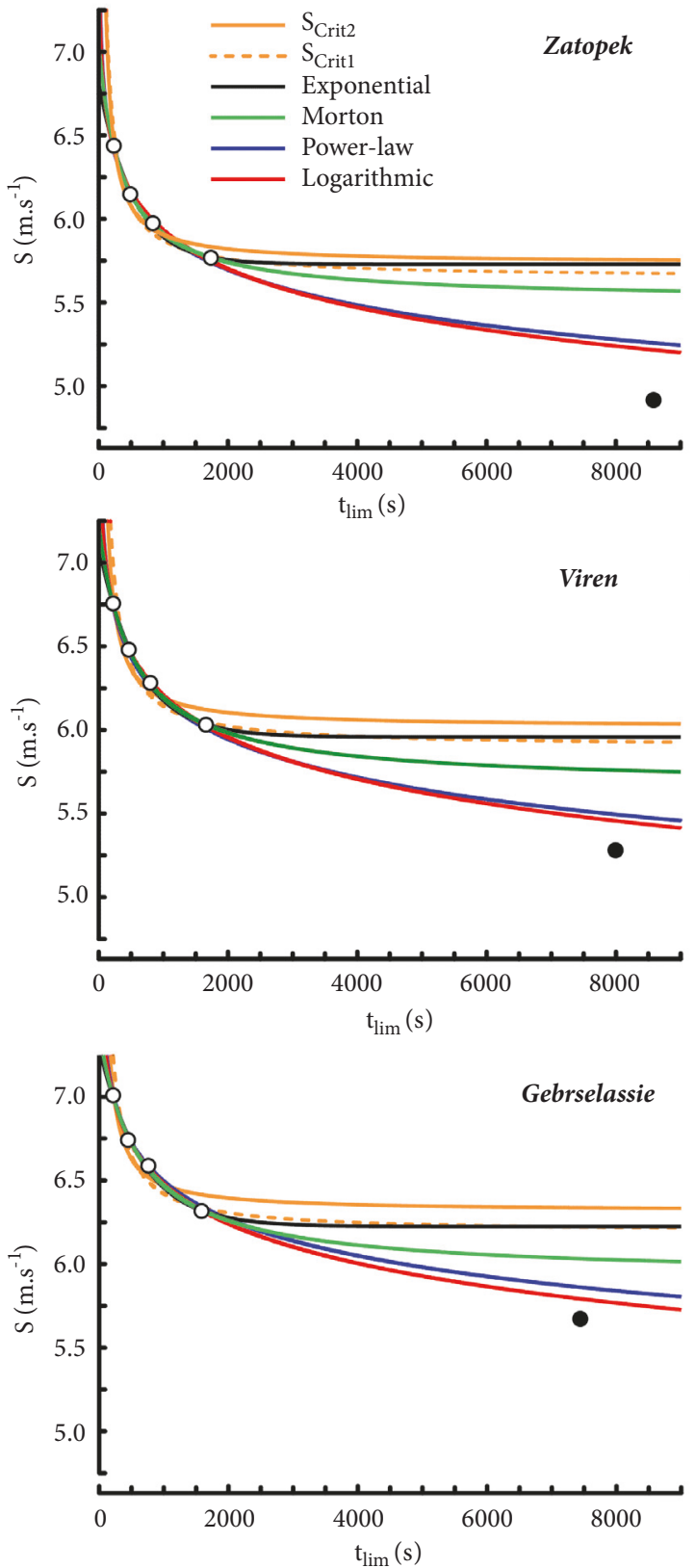

FIgURE 9: Comparisons of the relationship between $\left(t_{l i m}\right)$ and running speed $(S)$ of the logarithmic model, power-law model, $\mathrm{S}_{\text {Crit1 }}$ and $\mathrm{S}_{\text {Crit2 }}$ models, Morton's model, and exponential model computed from 4 distance performances $(1500,3000,5000$, and $10000 \mathrm{~m}$; empty circles) in the three runners who participated in marathon (black dots).

different hyperbolic models (Figure 3 and Tables 4, 6, and 8). When the individual critical speeds decreased because of a change in the range of performances, the corresponding ADC increased. These increases in $\mathrm{ADC}_{1}(79 \%)$ were much larger than the decreases in $\mathrm{S}_{\text {crit }}(3.8 \%)$ in the present study. The dependence of ADC on the range of performances can be verified (Figure 10) with the data of 19 elite endurance runners

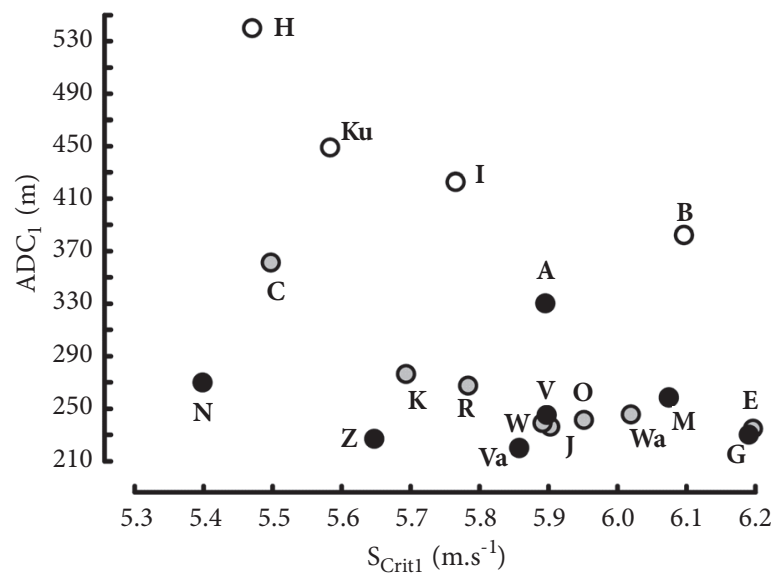

FIGURE 10: Relation between $\mathrm{S}_{\text {Critl }}$ and $\mathrm{ADC}_{1}$ in the 19 elite runners whose ranges of performances were different: 1500-10000 m (black dots), 5000-10000 m (empty circles), and 3000-5000 m (grey dots).

who were world-record holders and/or Olympic winners and/or world champions: Aouita (A), Bekele (B), Coe (C), El Gerrouj (E), Gebreselassie (G), Halberg (H), Ifter (I), Jazy (J), Keino (K), Kuts (Ku), Mo Farah (M), Nurmi (N), Ovett (O), Ryun (R), Väätäinen (Va), Viren (V), Wadoux (W), Walker (WA), and Zatopek (Z). The values of $\mathrm{ADC}_{1}$ were high (448 $\pm 67 \mathrm{~m}$ ) in elite runners whose data included 5000 and 10000 $\mathrm{m}$, only (empty circles). The values of $\mathrm{ADC}_{1}$ were lower (254 $\pm 38 \mathrm{~m}$ ) in elite runners whose data included all the distances from 1500 to $10000 \mathrm{~m}$ (black dots). In elite runners whose data did not include the $10000 \mathrm{~m}$ performances, $\mathrm{ADC}_{1}$ were intermediate $(263 \pm 43 \mathrm{~m})$. Moreover, the values of ADC are much higher in Morton's model (Table 8) than in $\mathrm{S}_{\text {Crit1 }}$ and $\mathrm{S}_{\text {Crit2 }}$ models (Tables 4 and 6). Therefore, the anaerobic capacity cannot be estimated from the hyperbolic models.

5.2. Endurance Indices. Parameter $\mathrm{E}$ of the logarithmic model by Péronnet and Thibault is an estimation of endurance capability $[7,8]$. However, the validity of parameter $\mathrm{E}$ as an endurance index is questionable because MAS is computed assuming that the value of $t_{\text {lim }}$ corresponding to MAS ( $t_{\text {MAS }}$ ) is equal to $7 \mathrm{~min}$ (420s) [7], which is contested. Indeed, in a review on the exhaustion time at $\mathrm{V}_{\mathrm{O}_{2}} \max$ [53], the value of $t_{\text {MAS }}$ was 6 min. In another study on the energetics of the best performances in middle distance running [9] the value of $t_{\text {MAS }}$ was estimated as equal to $14 \mathrm{~min}$. Therefore, the interest of parameter $\mathrm{E}$ as an endurance index can be questioned because it depends on $\mathrm{t}_{\mathrm{MAS}}$.

The effect of $t_{\mathrm{MAS}}$ on the endurance index by PéronnetThibault can be calculated [54]:

$$
\begin{aligned}
\mathrm{S} & =\alpha_{1}-\beta_{1} \ln \left(\frac{\mathrm{t}_{\mathrm{lim}}}{420}\right) \\
\mathrm{MAS}_{420} & =\alpha_{1} \\
\mathrm{E}_{420} & =\frac{100 \beta_{1}}{\alpha_{1}}
\end{aligned}
$$


If $\mathrm{T}=\mathrm{t}_{\mathrm{MAS}}$

$$
\begin{aligned}
\mathrm{S} & =\alpha_{2}-\beta_{2} \ln \left(\frac{\mathrm{t}_{\text {lim }}}{\mathrm{T}}\right) \\
\mathrm{MAS}_{\mathrm{T}} & =\alpha_{2} \\
\mathrm{E}_{\mathrm{T}} & =\frac{100 \beta_{2}}{\alpha_{2}} \\
\mathrm{~S} & =\left(\alpha_{1}+\beta_{1} \ln (420)\right)-\beta_{1} \ln \left(\mathrm{t}_{\text {lim }}\right) \\
\mathrm{S} & =\left(\alpha_{2}+\beta_{2} \ln (\mathrm{T})\right)-\beta_{2} \ln \left(\mathrm{t}_{\text {lim }}\right)
\end{aligned}
$$

The slopes between $\mathrm{S}$ and $\mathrm{t}_{\text {lim }}$ are the same. Therefore

$$
\begin{aligned}
\beta_{1} & =\beta_{2} \\
\mathrm{~S} & =\left(\alpha_{1}+\beta_{1} \ln (420)\right)-\beta_{1} \ln \left(\mathrm{t}_{\text {lim }}\right) \\
& =\left(\alpha_{2}+\beta_{1} \ln (\mathrm{T})\right)-\beta_{1} \ln \left(\mathrm{t}_{\lim }\right) \\
\alpha_{1}+\beta_{1} \ln (420) & =\alpha_{2}+\beta_{1} \ln (\mathrm{T}) \\
\alpha_{2} & =\alpha_{1}+\beta_{1} \ln (420)-\beta_{1} \ln (\mathrm{T}) \\
& =\alpha_{1}-\beta_{1} \ln \left(\frac{\mathrm{T}}{420}\right) \\
\frac{\mathrm{E}_{\mathrm{T}}}{} & =\frac{100 \beta_{2}}{\alpha_{2}}=\frac{100 \beta_{1}}{\left(\alpha_{1}-\beta_{1} \ln (\mathrm{T} / 420)\right.} \\
\frac{\mathrm{E}_{\mathrm{T}}}{\mathrm{E}_{420}} & =\frac{\left[100 \beta_{1} /\left(\alpha_{1}-\beta_{1} \ln (\mathrm{T} / 420)\right]\right.}{\left[100 \beta_{1} / \alpha_{1}\right]} \\
& =\frac{\alpha_{1}}{\left(\alpha_{1}-\beta_{1} \ln (\mathrm{T} / 420)\right)} \\
\frac{\mathrm{E}_{\mathrm{T}}}{\mathrm{E}_{420}} & =\frac{1}{\left(1-\left(\beta_{1} / \alpha_{1}\right) \ln (\mathrm{T} / 420)\right)} \\
& =\frac{1}{\left(1-\mathrm{E}_{420} \ln (\mathrm{T} / 420) / 100\right)}
\end{aligned}
$$

In Figure 11, this relationship between ratio $\mathrm{E}_{\mathrm{T}} / \mathrm{E}_{420}$ and $\mathrm{T}$ (see (35)) is computed for 3 theoretical runners: an elite endurance runner $\left(\mathrm{E}_{420}=4\right)$, a medium level endurance runner $\left(\mathrm{E}_{420}=\right.$ $8)$, and a low level endurance runner $\left(\mathrm{E}_{420}=16\right)$. The effect of $t_{\text {MAS }}$ is much more important in the low level endurance runner than in the elite endurance runner (Figure 10).

Large variations in $t_{\text {MAS }}$ have small effects on the classification of runners because the differences in $\mathrm{E}_{420}$ between elite and medium or low level runners are very large (from 4 to 16). For example, if $\mathrm{t}_{\mathrm{MAS}}$ is equal to $14 \mathrm{~min}$ instead of $7 \mathrm{~min}$, the medium level endurance runner would still be considered as a medium level endurance runner in spite of the increase of E (8.47 instead of 8). Similarly, the elite endurance runner would still be considered as an elite runner in spite of the increase in $\mathrm{E}$ (4.11 instead of 4) if $\mathrm{t}_{\mathrm{MAS}}$ is also equal to 14 min instead of $7 \mathrm{~min}$. On the other hand, if $\mathrm{t}_{\mathrm{MAS}}$ is equal to $4 \mathrm{~min}$ instead of $7 \mathrm{~min}$, the medium level endurance runner would still be considered as a medium level endurance runner in spite of the decrease in E (7.66 instead of 8.00). Similarly,

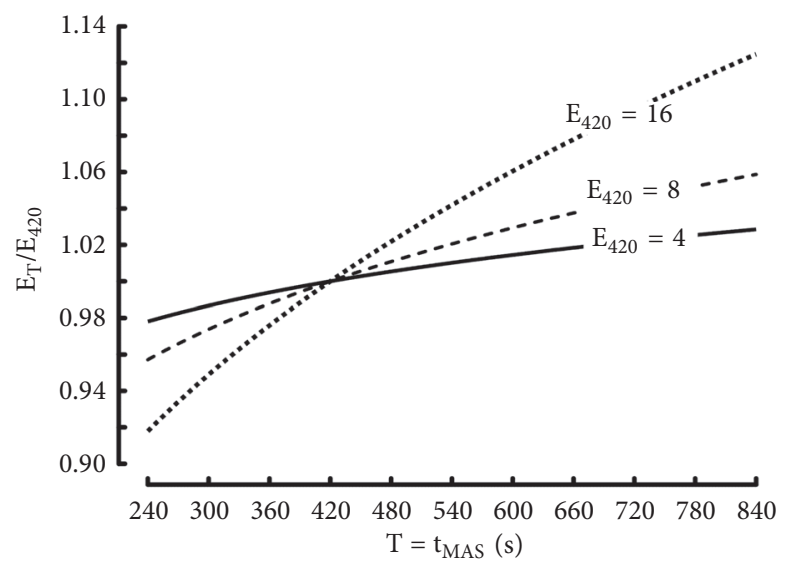

Figure 11: Effect of $t_{\text {MAS }}(T)$ on the ratio $E_{T} / E_{7 \min }$ for an elite endurance runner $\left(\mathrm{E}_{7 \min }=4\right)$, a medium level endurance runner $\left(\mathrm{E}_{7 \min }=8\right)$, and a low-level endurance runner $\left(\mathrm{E}_{7 \min }=16\right)$.

the low level endurance runner would still be considered as a low level endurance runner in spite of the decrease in E (14.7 instead of 16) if $\mathrm{t}_{\mathrm{MAS}}$ is also equal to $4 \mathrm{~min}$ instead of $7 \mathrm{~min}$.

The endurance capability can also be estimated by the asymptotic models if parameters $\mathrm{S}_{\text {Crit1 }}, \mathrm{S}_{\text {Crit2 }}, \mathrm{S}_{\text {Crit3 }}$, and $\mathrm{S}_{\infty}$ are normalised to maximal aerobic speed (MAS). However, the values of MAS computed from the asymptotic models also depend on $t_{\text {MAS. }}$. Therefore, the validity of these endurance indices is questionable.

Parameter $\mathrm{g}$ of the power-law model by Kennelly has a high interest because it can be demonstrated that exponent $g$ is a dimensionless index of endurance that does not depend on $t_{\mathrm{MAS}}$ unlike parameter $\mathrm{E}$ in the logarithmic model. The curvature of the $\mathrm{D}_{\lim }-\mathrm{t}_{\lim }$ equation depends on exponent g. In the elite endurance runners the $D_{\lim }-t_{l i m}$ equation is almost perfectly linear (Figure 2) whereas this equation is more curved in runners who are not endurance athletes. For example, exponent $g$ was close to 1 in elite endurance runners and lower than 0.9 in physical education students [55]. It can be demonstrated that exponent $g$ is equal to the ratio of the slope of the $D_{\lim }-t_{\text {lim }}$ equation to MAS when $t_{\text {lim }}$ is equal to $t_{\text {MAS. }}$. Indeed, the slope of $D_{\lim }-t_{\lim }$ is equal to the first derivative of the power-law equation. Therefore, the slope of the $D_{\lim }-t_{\text {lim }}$ equation is equal to

$$
\frac{\mathrm{dD}_{\lim }}{\mathrm{dt}_{\lim }}=\frac{\mathrm{d}\left(\mathrm{kt}_{\lim }^{\mathrm{g}}\right)}{\mathrm{dt}_{\lim }}=\mathrm{kgt}_{\lim }^{\mathrm{g}-1}
$$

For $t_{\text {lim }}$ equal to $t_{\text {MAS }}$, the running speed corresponds to MAS:

$$
\begin{aligned}
& \mathrm{S}=\mathrm{MAS}=\mathrm{kt}_{\mathrm{MAS}}{ }^{\mathrm{g}-1} \\
& \mathrm{k}=\frac{\mathrm{MAS}}{\left(\mathrm{t}_{\mathrm{MAS}}^{\mathrm{g}-1}\right)}=\mathrm{MASt}_{\mathrm{MAS}}{ }^{1-\mathrm{g}}
\end{aligned}
$$

Therefore

$$
\frac{\mathrm{dD}_{\lim }}{\mathrm{dt}_{\lim }}=\left(\text { MASt }_{\text {MAS }}{ }^{1-\mathrm{g}}\right)\left(\mathrm{gt}_{\lim }^{\mathrm{g}-1}\right)
$$




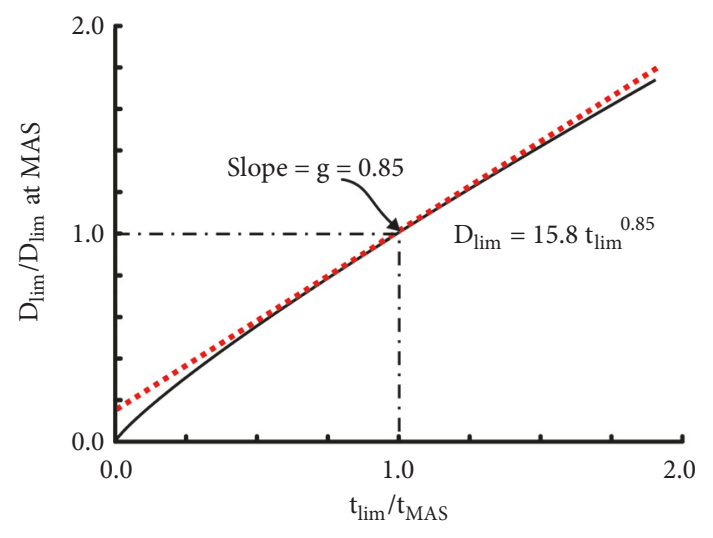

(a)

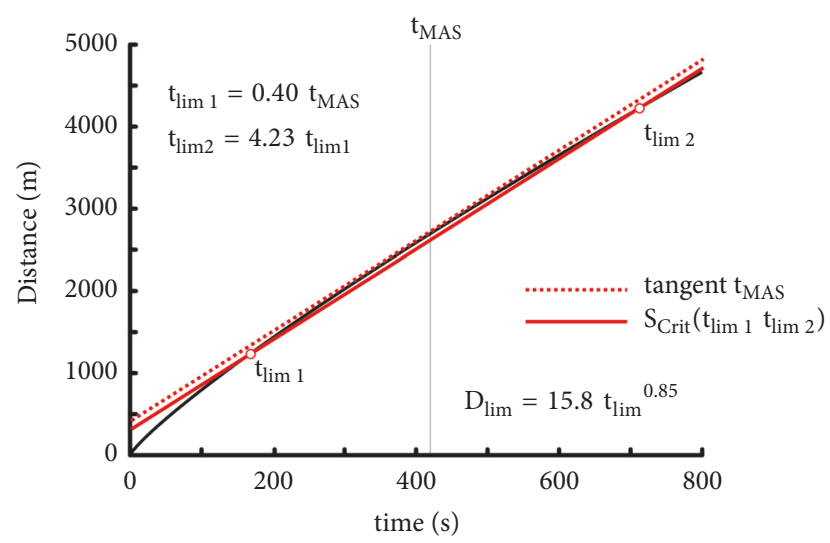

(b)

FIGURE 12: (a) Slope of the tangent at $t_{\text {MAS }}$ of the curve corresponding to the power-law model with $t_{\text {lim }}$ normalised to $t_{\text {MAS }}$ and $D_{\text {lim }}$ normalised to $\mathrm{D}_{\lim }$ at maximal aerobic speed (MAS). (b) Comparison of a critical speed computed from two values of $\mathrm{t}_{\lim }$ with the tangent at $\mathrm{t}_{\mathrm{MAS}}(420 \mathrm{~s})$.

When $\mathrm{t}_{\lim }=\mathrm{t}_{\mathrm{MAS}}$,

$$
\begin{aligned}
\frac{\mathrm{dD}_{\text {lim }}}{\mathrm{dt}_{\text {MAS }}} & =\left(\text { MASt }_{\text {MAS }}{ }^{1-g}\right)\left(\mathrm{gt}_{\text {MAS }}{ }^{g-1}\right) \\
& =\text { gMAS } \\
\frac{\left(\mathrm{dD}_{\text {lim }} / \mathrm{dt}_{\text {MAS }}\right)}{\text { MAS }} & =g
\end{aligned}
$$

Consequently, the ratio of the $\mathrm{D}_{\lim } \mathrm{t}_{\text {lim }}$ slope to MAS corresponding to $t_{\text {MAS }}$ is equal to exponent $g$ and is independent of $t_{\text {MAS }}$ unlike the endurance indices computed from the other models. In Figure 12(a), $\mathrm{D}_{\text {lim }}$ and $\mathrm{t}_{\text {lim }}$ are normalised to $\mathrm{D}_{\mathrm{MAS}}$ $\left(\mathrm{D}_{\lim }\right.$ at MAS) and $\mathrm{t}_{\mathrm{MAS}}$, respectively.

$$
\begin{aligned}
\frac{D_{\text {lim }}}{D_{\text {MAS }}} & =\frac{D_{\text {lim }}}{\left(t_{\text {MAS }} \text { MAS }\right)}=\frac{k t_{\text {lim }}{ }^{g}}{\left(t_{\text {MAS }} M A S\right)} \\
& =\frac{\left(\text { MAS } /\left(t_{\text {MAS }}{ }^{g-1}\right)\right) t_{\text {lim }}{ }^{g}}{\left(t_{\text {MAS }} \text { MAS }\right)}=\left(\frac{t_{\text {lim }}}{t_{\text {MAS }}}\right)^{g}
\end{aligned}
$$

The slope of the line joining two points corresponding to $t_{\lim 1}$ and $t_{\lim 2}$ of the $D_{\lim }-t_{\lim }$ curve in Figure $12(\mathrm{~b})$ is equal to exponent $\mathrm{g}$ when it is parallel to the tangent of the curve

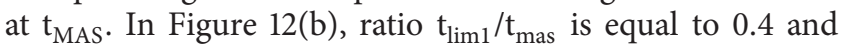
ratio $t_{\lim 2} / t_{\lim 1}$ is equal to 4.23 . In many studies on $S_{\text {Crit }}$ (or $\mathrm{P}_{\text {Crit }}$ ) the range of $\mathrm{t}_{\text {lim }}$ is from 3 to $15 \mathrm{~min}$, which corresponds to $t_{\lim 1}$ equal to about 0.4-0.5 $t_{\text {MAS }}$ (if $t_{\text {MAS }}$ corresponds to 7 or $6 \mathrm{~min}$ ) and ratio $t_{\lim 2} / t_{\lim 1}$ about $4-5$. This range of $t_{\lim }$ also corresponds to the performances on 1500 and $5000 \mathrm{~m}$ in endurance runners. In the present study, when $S_{\text {Critl }}$ is computed from 1500-3000-5000m and is normalised to $S_{420}$ (Table 14), the value of $S_{\text {Crit1 }} / S_{420}$ is equal to $0.934 \pm 0.016$ and is significantly correlated $(\mathrm{r}=0.976 ; \mathrm{P}<0.001)$ to $\mathrm{g}$ $(0.934 \pm 0.16)$. The product of exponent $g$ and MAS is the equivalent of a critical speed computed from a 3-15-minute $t_{\lim }$ range. For example, the product of exponent $g$ and $S_{420}$ estimated from power-law model (Table 14) is equal to 6.04 $\pm 0.30 \mathrm{~m} \cdot \mathrm{s}^{-1}$ and is significantly correlated $(\mathrm{r}=0.998 ; \mathrm{P}<$ $0.001)$ with $S_{\text {Crit1 }}$ that is slightly but significantly $(\mathrm{P}=0.031)$ lower $\left(5.99 \pm 0.31 \mathrm{~m} . \mathrm{s}^{-1}\right)$. The similar values of $\mathrm{S}_{\mathrm{Crit}} / \mathrm{S}_{420}$ and $\mathrm{g}$ and the close values of $\mathrm{S}_{\text {Critl }}$ and product $\mathrm{g} * \mathrm{~S}_{420}$ and their significant correlation confirm the hypothesis that exponent $\mathrm{g}$ is an endurance index.

5.3. Correlations between the Parameters of the Different Models. The correlation between $g$ and $\mathrm{E}$ was highly significant ( $\mathrm{r}=0.999$, Table 19), which confirms the hypothesis that exponent $\mathrm{g}$ is an endurance index. Parameters $\mathrm{S}_{\mathrm{Crit1}}, \mathrm{S}_{\mathrm{Crit2}}$, $S_{\text {Crit3 }}$, and $S_{\infty}$ were highly correlated $(P \geq 0.965)$. These parameters that depend not only on endurance capability but also on maximal aerobic speed were not correlated with dimensionless parameters $g$ and $E(r \leq 0.551)$. When $\mathrm{S}_{\text {Crit1 }}, \mathrm{S}_{\text {Crit3 }}$, and $\mathrm{S}_{\infty}$ were normalised to an estimate of maximal aerobic speed $\left(S_{420}\right)$ computed from their model (Table 14), these parameters became dimensionless. The value of $\mathrm{S}_{\mathrm{Crit} 1} / \mathrm{S}_{420}$ was significantly correlated with the dimensionless indices $\mathrm{g}$, and $\mathrm{E}$ (Table 19). After normalisation to $\mathrm{S}_{420}$, the correlation coefficients between $S_{\text {Crit3 }} / S_{420}$ or $S_{\infty} / S_{420}$ and E or $g$ increased $(r \geq 0.676)$ but were not significant perhaps because of the small number of runners. Indeed, a correlation coefficient equal to 0.6664 would have been significant if there were 9 runners.

A study [56] compared the critical speeds from different mathematical models in 12 middle- or long-distance male runners on a track in order to determine which model provides the most accurate prediction of performance in 1 hour. In this latter study, the parameters $\mathrm{S}_{\mathrm{Crit} 1}, \mathrm{~S}_{\mathrm{Crit} 2}, \mathrm{~S}_{\mathrm{Crit} 3}$, and $S_{\infty}$ were also significantly correlated $(0.85<\mathrm{r}<0.99$, $\mathrm{p}<0.01)$ and the differences between these different critical speeds were the same as in the present study for the 1500-5000 $\mathrm{m}$ range: $\mathrm{S}_{\text {Crit3 }}<\mathrm{S}_{\text {Crit1 }}<\mathrm{S}_{\text {Crit } 2}<\mathrm{S}_{\mathrm{\infty}}$.

The meaning of parameters $S_{\mathrm{Max}}$ (Morton's Model) and $\mathrm{S}_{0}$ (exponential model) is identical and corresponds, in theory, to maximum running speed. When $S_{\text {Max }}$ and $S_{0}$ 
were computed from the 4 distance performances (from 1500 to10000 m, Tables 8 and 12), these parameters were significantly correlated $(\mathrm{r}=0.824 ; \mathrm{P}=0.044)$. However, $\mathrm{S}_{\mathrm{Max}}$ was significantly higher than $\mathrm{S}_{0}(\mathrm{P}=0.31)$. When $\mathrm{S}_{\mathrm{Max}}$ and $\mathrm{S}_{0}$ were computed from the 3 distance performances (from 1500 to $5000 \mathrm{~m}$ ) their values were higher. A previous study [57] compared which parameter $\left(\mathrm{S}_{\mathrm{Max}}\right.$ or $\left.\mathrm{S}_{0}\right)$ is closest to maximum speed by measuring maximal velocity during a sprint. The values of $\mathrm{S}_{\mathrm{Max}}$ and $\mathrm{S}_{0}$ were well correlated $(\mathrm{r}=$ $0.93, \mathrm{P}<0.001)$ but they were significantly different. As in the present study, $\mathrm{S}_{\mathrm{Max}}\left(7.80 \pm 0.93 \mathrm{~m} . \mathrm{s}^{-1}\right)$ was higher than $\mathrm{S}_{0}$ (7.49 $0.90 \mathrm{~m} . \mathrm{s}^{-1}$ ) but lower than the actual maximum speed $\left(8.43 \pm 0.33 \mathrm{~m} . \mathrm{s}^{-1}\right)$ on a track. However, $\mathrm{S}_{\mathrm{Max}}$ and $\mathrm{S}_{0}$ were computed from the performances on a treadmill whereas the actual maximum running speed was measured on a track during short sprints with photocells placed at 30 and $40 \mathrm{~m}$. It is likely that it would be better to measure actual maximum speed during a $60 \mathrm{~m}$ sprint on a track with a laser apparatus and to compare it with $\mathrm{S}_{\mathrm{Max}}$ and $\mathrm{S}_{0}$ from Morton's model and exponential models computed from performances on a track instead of a treadmill.

In the present study, parameter $\mathrm{k}$ of the power-law model was $25 \%$ higher than $\mathrm{S}_{\mathrm{Max}}$ and $31 \%$ higher than $\mathrm{S}_{0}$. However, $\mathrm{k}$ was significantly correlated with $\mathrm{S}_{\mathrm{Max}}$ and $\mathrm{S}_{0}$. These results confirm the hypothesis that parameter $\mathrm{k}$ should be correlated with the maximal running speed because it is equal to the running speed corresponding to one second. However, the value of $\mathrm{k}$ depends on the time unit. If the running performances are evaluated in minutes, parameter $\mathrm{k}$ would be equal to the maximal speed corresponding to 1 minute whereas $\mathrm{S}_{\mathrm{Max}}$ and $\mathrm{S}_{0}$ would still correspond to maximal running speed but expressed in $\mathrm{m} \cdot \mathrm{min}^{-1}$.

5.4. Prediction of Long Distances. The asymptotes of hyperbolic and exponential model correspond to $\mathrm{S}_{\text {Crit1 }}, \mathrm{S}_{\text {Crit2 }}$, $\mathrm{S}_{\text {Crit3 }}$, and $\mathrm{S}_{\infty}$, respectively. In these models, the speeds lower than these asymptotes can be maintained infinitely. Therefore, the extrapolations of the asymptotic hyperbolic and exponential models overestimate the running speeds on very long distances (Figure 9). In fact, power-law and logarithmic models are also asymptotic models but these asymptotes are equal to zero.

The overestimations of marathon performances from the extrapolations of power-law and logarithmic models (Figures 1(b), 6(b), and 9) are much smaller. Similarly, the computations of 30-minute and 60-minute running speeds by extrapolation of the asymptotic models (Table 7) were probably overestimations whereas the extrapolations of the power-law and logarithmic models were probably close to the actual running speeds.

The overestimations of marathon performances by the logarithmic and power-law models (Figures 1, 6, and 9) are probably due not only to the causes of fatigue in long distances [58] but, perhaps, also to the effects of ground (track versus road, slopes, etc.), wind, shoes, and age.

5.5. Which Is the Optimal Empirical Model? The optimal running model is an accurate, useful, and practical model.
5.5.1. Which Is the Most Accurate Model? When computed from 4 distances, the individual correlation coefficients of all the models were high in all the elite runners. The correlation coefficients were the highest for the 3-parameter models by Morton and Hopkins and they were equal to 1 when they were computed from 3 distances only. These correlation coefficients equal to 1 were expected. Similarly, the regression coefficients of all the 2-parameter running models would have been equal to 1 , if they were computed with only two distances.

The values of RMSE were the lowest for the 3-parameter models (Table 17). Morton's model was the most accurate as demonstrated by the ratios of estimated to actual running speeds which were very close to 1 for each distance (Table 9). Indeed, the differences between the estimated to actual running speeds were lower than $0.5 \%$ in each distance for all the runners. This model was significantly more accurate than all the other models as shown in Table 18.

However, if a running model is perfect, there should be no significant difference between its parameters computed from different ranges of distances. Morton's model was probably not perfect because its parameters were significantly different $(\mathrm{P}=0.031)$ when they were computed from different ranges of distances. In the present study, the empirical models consist of single equations and are less complex than the physiological and biomechanical models, which probably explained that the parameters of all these empirical models depended on the range of $t_{\text {lim }}$. Indeed, the causes of fatigue differ for short, medium, and long distances [58].

The $\mathrm{S}_{\mathrm{Crit} 1}$ and $\mathrm{S}_{\mathrm{Crit} 2}$ models and the concepts of critical speed (or critical power) are by far the most used and taught $[21,46]$. Nonetheless, $\mathrm{S}_{\mathrm{Crit1}}$ and $\mathrm{S}_{\mathrm{Crit} 2}$ models were the less accurate models for the relationship between running speed and $t_{\text {lim }}$. The curves derived from (12) and (14) did not describe accurately the relationships between speed and $\mathrm{t}_{\lim }$ (Figures $4(\mathrm{~b})$ and $4(\mathrm{c})$ ). The only points corresponding to $10000 \mathrm{~m}$ performances were close to the curves derived from (12) whereas the only points corresponding to $1500 \mathrm{~m}$ performances were close to the curves derived from (14). Consequently, the speed- $t_{\lim }$ relationship would be better described by the mean values of ADC and $S_{\text {Crit }}$ :

$$
\begin{gathered}
\mathrm{ADC}=\frac{\left(\mathrm{ADC}_{1}+\mathrm{ADC}_{2}\right)}{2}=\frac{\left(\alpha_{1}+\beta_{2}\right)}{2} \\
\mathrm{~S}_{\text {Crit }}=\frac{\left(\mathrm{S}_{\text {Crit } 1}+\mathrm{S}_{\text {Crit } 2}\right)}{2}=\frac{\left(\alpha_{2}+\beta_{1}\right)}{2}
\end{gathered}
$$

Even if the description of the individual speed- $t_{\lim }$ relationships was better with the curves computed from the mean values of ADC and $S_{\text {Crit }}$ in (12) and (14) (Figure 13), this new hyperbolic model is not optimal when it is compared with the figures of the other models.

5.5.2. Which Is the Most Useful Model? The empirical models of running exercises are often used to estimate the running speeds over given distances, the endurance capability, and MAS. The race performance calculation requires 2 or 3 parameters depending on the model used. On the other hand, for each running model in the present study, there is only one 


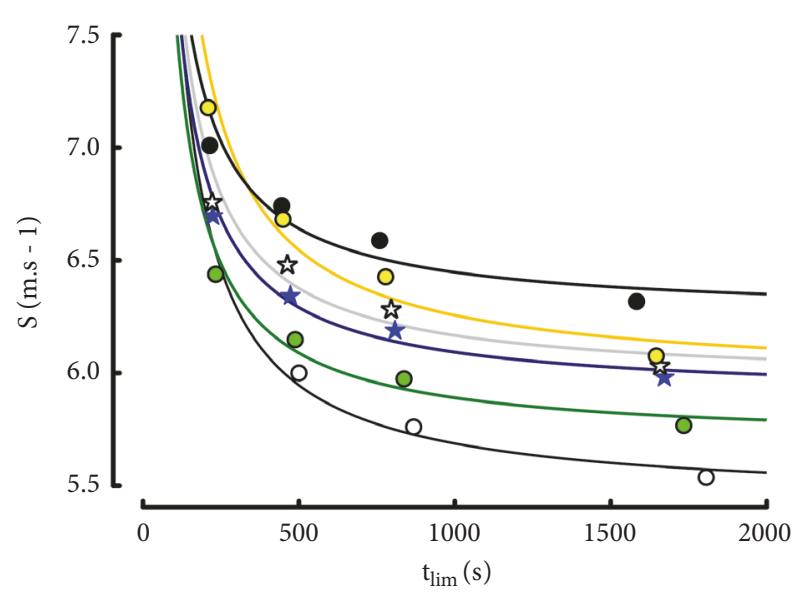

FIGURE 13: Individual relationships between speed and $t_{\text {lim }}$ computed from the mean values of ADC and $\mathrm{S}_{\text {Crit }}$ in (12) and (14).

parameter that is an expression of the long-distance running capability. Indeed, parameter ADC in the hyperbolic models is not reliable and parameters $\mathrm{k}, \mathrm{S}_{\mathrm{Max}}$, and $\mathrm{S}_{0}$ that are maximal speed indices are probably not useful for endurance runners. Similarly the parameter corresponding to the time constant $(\tau)$ in Hopkins' model is not useful.

The useful parameters of the asymptotic model correspond to $\mathrm{S}_{\text {Crit1 }}, \mathrm{S}_{\mathrm{Crit} 2}, \mathrm{~S}_{\text {Crit3 }}$, and $\mathrm{S}_{\infty}$. In theory, these parameters represent the fastest speed that can be maintained for a very long time. However, when $S_{\text {Crit1 }}$ was computed from exercises shorter than $20 \mathrm{~min}$, the subjects were generally only able to maintain $S_{\text {Critl }}$ for less than $30 \mathrm{~min}$ and the running velocities that could be maintained for 60 minutes on a treadmill were largely overestimated by $S_{\text {Crit1 }}$ [59]. In another study on the relationship between critical velocity and marathon performance [60], $\mathrm{S}_{\text {Crit1 }}\left(4.43 \mathrm{~m} . \mathrm{s}^{-1}\right)$ was $44 \%$ faster than the marathon running speed $\left(3.07 \mathrm{~m} . \mathrm{s}^{-1}\right)$. Nonetheless, the correlation between marathon performance and $\mathrm{S}_{\text {Crit1 }}$ was more significant than the correlations with the other physiological parameters. In this latter study, it was possible to calculate an approximation of the marathon performance from $\mathrm{S}_{\text {Critl }}(\mathrm{r}=0.87$ and $\mathrm{SEE}=14 \mathrm{~min})$. Approximations of long-distance performances $(>10000 \mathrm{~m}$ ) are probably also possible with $\mathrm{S}_{\mathrm{Crit} 2}, \mathrm{~S}_{\mathrm{Crit} 3}$, and $\mathrm{S}_{\infty}$ since they are highly correlated with $S_{\text {Crit1 }}(P \geq 0.965)$. For example, in the study on 12 trained middle- and long-distance male runners [56], the correlation coefficients of $S_{\text {Crit1 }}, S_{\text {Crit2 }}$, and $\mathrm{S}_{\infty}$ with the maximal running speed during $60 \mathrm{~min}$ were equal to $0.90,0.91$, and 0.93 , respectively. Amazingly, the correlation coefficient with the 60-min running speed was the lowest (0.80) for $\mathrm{S}_{\mathrm{Crit} 3}$ in these middle- and long-distance runners but the overestimation was the smallest $(0.13 \pm 0.21$ $\mathrm{m} . \mathrm{s}^{-1}$ ) as in the present study.

It is likely that the logarithmic and power-law models that are not asymptotic are the best empirical models for the predictions of very long distances by extrapolation as suggested in Table 15 and Figure 9. The predictions of the running speeds corresponding to $30 \mathrm{~min}, 60 \mathrm{~min}$, and marathon by extrapolation of Morton's model were higher than the same predictions from the logarithmic and powerlaw models. But the overestimations of the running speeds corresponding to $30 \mathrm{~min}, 60 \mathrm{~min}$, and marathon by Morton's model were lower than the overestimations by the other asymptotic models (Tables 15 and 16 and Figure 9). On the other hand, the predictions of competition performances between 1500 and $10000 \mathrm{~m}$ (for example, one or two miles or $2000 \mathrm{~m}$ ) by interpolation should be better with the 3parameter models by Morton or Hopkins whose accuracies were the best. Similarly, the running speed corresponding to 6 or $7 \mathrm{~min}$ (an estimation of MAS) should be more accurate when computed with these 3-parameter models.

The endurance index of the power-law model (exponent g) should be the most useful since it is the only endurance index that does not depend on $\mathrm{t}_{\mathrm{MAS}}$ (Section 5.2).

5.5.3. Which Is the Most Practical? The most practical model should be the less sensitive to a slightly submaximal performance and the easiest to compute.

Unfortunately, no study compares the sensitivity of the different models to submaximal performances. However, in a previous study [61], some results were assumed to be the effect of submaximal performances on $\mathrm{S}_{\text {Crit1 }}$ model whose sensitivity was discussed in a review on the critical power concept [16]. Similarly, the values of parameter $\mathrm{k}$ that is an index of maximal running speed were overestimated in several physical education students in a previous study [55], which was probably the effect of submaximal running performances. Indeed, in 4 physical education students, parameters $\mathrm{k}$ were largely overestimated since they were higher than $20 \mathrm{~m} . \mathrm{s}^{-1}$, whereas the maximal running speed is about $12.2 \mathrm{~m} . \mathrm{s}^{-1}$ for the best world sprinter U. Bolt [62]. The comparison of parameters $\mathrm{k}$ of Ovett and Coe [63] is also a demonstration of the effects of submaximal performances on the modelling of running performances with the power-law model. Indeed, the differences between Ovett and Coe for the performances over 800,1500, and $2000 \mathrm{~m}$ are around 1 second but the inclusion of longer distances (3000 $\mathrm{m}$ and $5000 \mathrm{~m}$ ) causes large differences in the values of $\mathrm{k}$ and $\mathrm{g}$. The value of $\mathrm{k}$ was largely higher than $12 \mathrm{~m} . \mathrm{s}^{-1}$ for Coe but not for Ovett. The best performance for a given distance is probably maximal if the elite runner has run this distance many times, which was not the case for Coe in the $3000 \mathrm{~m}$ and $5000 \mathrm{~m}$ distances. In the present study, the sensitivity of Morton's model to submaximal performances could be not negligible. Indeed, the parameters of this model were significantly different when they were computed from different distance ranges although the differences between the estimated and the actual speeds were very low $(<0.5 \%)$. The sensitivity of Morton's model to submaximal performances could also explain why the correlation coefficient of $S_{\text {Crit3 } 3}$ with the 60 min speed was the lowest in the study on the twelve middle- and long-distance runners [56].

Many runners compete over two distances, only (either 800 and $1500 \mathrm{~m}$ or 5000 and $10000 \mathrm{~m}$ or half-marathon and marathon). Their performances on the other distances could be slightly submaximal and, consequently, the 3-parameter 
models by Morton or Hopkins could be not optimal for these runners.

The 3-parameter models need a software that can compute the parameters by iteration. The 2-parameter models are easier to compute either by a nomogram [48] or by the current database software (Microsoft Excel, LibreOffice Calc, etc.). The calculation of $\mathrm{S}_{\text {Crit1 }}$ is much easier than the parameters of the other models. Particularly, it is very easy to calculate $\mathrm{S}_{\text {Crit1 }}$ from two running performances:

$$
S_{\text {Crit1 }}=\frac{\left(D_{\lim 2}-D_{\lim 1}\right)}{\left(t_{\lim 2}-t_{\lim 1}\right)}
$$

In addition, the $S_{\text {Critl }}$ model is the only model that can directly predict the performance corresponding to a distance from its parameters $\left(\mathrm{ADC}_{1}\right.$ and $\left.\mathrm{S}_{\mathrm{Crit1}}\right)$ :

$$
\begin{gathered}
\mathrm{D}_{\text {lim }}=\mathrm{ADC}_{1}+\mathrm{S}_{\text {Critl }} * \mathrm{t}_{\text {lim }} \\
\mathrm{t}_{\text {lim }}=\frac{\left(\mathrm{D}_{\text {lim }}-\mathrm{ADC}_{1}\right)}{\mathrm{S}_{\text {Crit } 1}}
\end{gathered}
$$

In the present study, the other models can only predict performances corresponding to a value of $t_{\text {lim }}$. In these models, the protocol presented in Section 3.3 is necessary for the prediction of a performance corresponding to a distance.

\section{Conclusion}

The comparison of the accuracies of the different models in the six elite endurance runners suggests that the most accurate model is the asymptotic 3-parameter hyperbolic model proposed by Morton and that the less accurate models are $\mathrm{S}_{\text {Crit1 }}$ and $\mathrm{S}_{\text {Crit2 }}$ models which are the most often used. However, it is likely that logarithmic and power-law models are the most accurate models for the predictions of longdistance performances (maximal running speeds for 30 and 60 min or marathon) by extrapolation. In addition, exponent $\mathrm{g}$ of the power-law model is an interesting endurance index

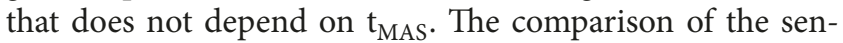
sitivity of the different models to submaximal performances should be studied to select the most practical model.

\section{Data Availability}

All the "experimental" data are presented in Table 1. All the results of the computations according to the different models are presented in the next 15 tables (from Table 2 to Table 16).

\section{Conflicts of Interest}

The author declares that they have no conflicts of interest.

\section{References}

[1] A. V. Hill, Muscular Movement in Man: The Factors Governing Speed and Recovery from Fatigue, McGraw-Hill, New York, NY, USA, London, UK, 1927.

[2] F. M. Henry, "Time-velocity equations and oxygen requirements of "all-out" and "steady-pace" running," Research Quarterly for Exercise and Sport, vol. 25, no. 2, pp. 164-177, 1954.
[3] D. L. Costill, "The relationship between selected physiological variables and distance running performance," The Journal of Sports Medicine and Physical Fitness, vol. 7, no. 2, pp. 61-66, 1967.

[4] J. B. Keller, "A theory of competitive running," Physics Today, vol. 26, no. 9, pp. 43-47, 1973.

[5] R. Margaria, P. Aghemo, and F. Pineral Limas, "A simple relation between performance in running and maximal aerobic power," Journal of Applied Physiology, vol. 38, no. 2, pp. 351-352, 1975.

[6] A. J. Ward-Smith, "A mathematical theory of running, based on the first law of thermodynamics, and its application to the performance of world-class athletes," Journal of Biomechanics, vol. 18, no. 5, pp. 337-349, 1985.

[7] F. Péronnet and G. Thibault, "Analyse physiologique de la performance en course à pied : révision du modèle hyperbolique," Journal de Physiologie Paris, vol. 82, pp. 52-60, 1987.

[8] F. Peronnet and G. Thibault, "Mathematical analysis of running performance and world running records," Journal of Applied Physiology, vol. 67, no. 1, pp. 453-465, 1989.

[9] P. E. di Prampero, "Factors limiting maximal performance in humans," European Journal of Applied Physiology, vol. 90, no. 34, pp. 420-429, 2003.

[10] P. E. Di Prampero, C. Capelli, P. Pagliaro et al., "Energetics of best performances in middle-distance running," Journal of Applied Physiology, vol. 74, no. 5, pp. 2318-2324, 1993.

[11] A. J. Ward-Smith, "The bioenergetics of optimal performances in middle-distance and long- distance track running," Journal of Biomechanics, vol. 32, no. 5, pp. 461-465, 1999.

[12] A. E. Kennelly, "An approximate law of fatigue in the speeds of racing animals," Proceedings of the American Academy of Arts and Sciences, vol. 42, no. 15, pp. 275-331, 1906.

[13] W. G. Hopkins, I. M. Edmond, B. H. Hamilton, D. J. Mac Farlane, and B. H. Ross, "Relation between power and endurance for treadmill running of short duration," Ergonomics, vol. 32, no. 12, pp. 1565-1571, 1989.

[14] R. H. Morton and D. J. Hodgson, "The relationship between power output and endurance: A brief review," European Journal of Applied Physiology, vol. 73, no. 6, pp. 491-502, 1996.

[15] R. Hugh Morton, "A 3-parameter critical power model," Ergonomics, vol. 39, no. 4, pp. 611-619, 1996.

[16] H. Vandewalle, J. F. Vautier, M. Kachouri, J.-M. Lechevalier, and $\mathrm{H}$. Monod, "Work-exhaustion time relationships and the critical power concept," The Journal of Sports Medicine and Physical Fitness, vol. 37, no. 2, pp. 89-102, 1997.

[17] R. H. Morton, "The critical power and related whole-body bioenergetic models," European Journal of Applied Physiology, vol. 96, no. 4, pp. 339-354, 2006.

[18] L. V. Billat, J. P. Koralsztein, and R. H. Morton, “Time in human endurance models: From empirical models to physiological models," Sports Medicine, vol. 27, no. 6, pp. 359-379, 1999.

[19] V. Bocquet and V. Billat, "Modèles mathématiques et physiologiques de la performance humaine," Science \& Sports, vol. 14, no. 6, pp. 278-291, 1999.

[20] L. Bosquet, L. Léger, and P. Legros, "Methods to determine aerobic endurance," Sports Medicine, vol. 32, no. 11, pp. 675-700, 2002.

[21] D. C. Clarke and P. F. Skiba, "Rationale and resources for teaching the mathematical modeling of athletic training and performance," American Journal of Physiology - Advances in Physiology Education, vol. 37, no. 2, pp. 134-152, 2013.

[22] J. Dekerle, X. Nesi, and H. Carter, "The distance - Time relationship over a century of running Olympic performances: A 
limit on the critical speed concept," Journal of Sports Sciences, vol. 24, no. 11, pp. 1213-1221, 2006.

[23] P. T. Nikolaidis, M. A. Zingg, and B. Knechtle, "Performance trends in age-group runners from $100 \mathrm{~m}$ to marathon-The World Championships from 1975 to 2015," Scandinavian Journal of Medicine \& Science in Sports, vol. 27, no. 12, pp. 1588-1596, 2017.

[24] R. Lepers and P. J. Stapley, "Master athletes are extending the limits of human endurance," Frontiers in Physiology, vol. 7, 2016.

[25] S. N. Cheuvront, R. Carter III, K. C. Deruisseau, and R. J. Moffatt, "Running performance differences between men and women: An update," Sports Medicine, vol. 35, no. 12, pp. 10171024, 2005.

[26] M. J. Joyner, "Physiological limits to endurance exercise performance: influence of sex," The Journal of Physiology, vol. 595, no. 9, pp. 2949-2954, 2017.

[27] F. Péronnet, Le Marathon. Deuxième édition, Vigot Edition, Paris, 1991.

[28] B. Baron, T. D. Noakes, J. Dekerle et al., "Why does exercise terminate at the maximal lactate steady state intensity?" British Journal of Sports Medicine, vol. 42, no. 10, pp. 828-833, 2008.

[29] P. Fontana, U. Boutellier, and C. Knöpfli-Lenzin, "Time to exhaustion at maximal lactate steady state is similar for cycling and running in moderately trained subjects," European Journal of Applied Physiology, vol. 107, no. 2, pp. 187-192, 2009.

[30] R. Beneke, R. M. Leithäuser, and O. Ochentel, "Blood lactate diagnostics in exercise testing and training," International Journal of Sports Physiology and Performance, vol. 6, no. 1, pp. 8-24, 2011.

[31] S. Savaglio and V. Carbone, "Scaling in athletic world records," Nature, vol. 404, no. 6775, p. 244, 2000.

[32] V. Carbone and S. Savaglio, "Scaling laws and forecasting in athletic world records," Journal of Sports Sciences, vol. 19, no. 7, pp. 477-484, 2001.

[33] W. G. Hopkins and D. J. Hewson, "Variability of competitive performance of distance runners," Medicine \& Science in Sports \& Exercise, vol. 33, no. 9, pp. 1588-1592, 2001.

[34] J. S. Katz and L. Katz, "Power laws and athletic performance," Journal of Sports Sciences, vol. 17, no. 6, pp. 467-476, 1999.

[35] J. M. García-Manso and J. M. Martín-González, "Laws of Potency or scale: its application to the sportive phenomenon," Fitness and Performance Journal, vol. 7, no. 3, pp. 195-202, 2008.

[36] P. S. Riegel, "Athletic records and human endurance," American Scientist, vol. 69, no. 3, pp. 285-299, 1981.

[37] A. J. Vickers and E. A. Vertosick, "An empirical study of race times in recreational endurance runners," BMC Sports Science, Medicine and Rehabilitation, vol. 8, no. 1, 2016.

[38] J. Scherrer, M. Samson, and A. Paléologue, "Etude du travail musculaire et de la fatigue. Données ergométriques obtenues chez l'homme," Journal de Physiologie, vol. 46, pp. 887-916, 1954.

[39] H. Monod and J. Scherrer, "The work capacity of a synergic muscular group," Ergonomics, vol. 8, no. 3, pp. 329-338, 1965.

[40] J. H. Ettema, "Limits of human performance and energyproduction," Internationale Zeitschrift für Angewandte Physiologie Einschließlich Arbeitsphysiologie, vol. 22, no. 1, pp. 45-54, 1966.

[41] J. Scherrer and H. Monod, "Le travail musculaire local et la fatigue chez l'Homme," Journal de Physiologie, Paris, vol. 52, pp. 419-501, 1960.
[42] J. F. Vautier, H. Vandewalle, H. Arabi, and H. Monod, "Critical power as an endurance index," Applied Ergonomics, vol. 26, no. 2, pp. 117-121, 1995.

[43] D. Bishop, D. G. Jenkins, and A. Howard, "The critical power function is dependent on the duration of the predictive exercise tests chosen," International Journal of Sports Medicine, vol. 19, no. 2, pp. 125-129, 1998.

[44] T. Moritani, A. N. Ata, H. A. Devries, and M. Muro, "Critical power as a measure of physical work capacity and anaerobic threshold," Ergonomics, vol. 24, no. 5, pp. 339-350, 1981.

[45] R. L. Hughson, C. J. Orok, and L. E. Staudt, "A high velocity treadmill running test to assess endurance running potential," International Journal of Sports Medicine, vol. 5, no. 1, pp. 23-25, 1984.

[46] D. C. Poole, M. Burnley, A. Vanhatalo, H. B. Rossiter, and A. M. Jones, "Critical power: An important fatigue threshold in exercise physiology," Medicine \& Science in Sports \& Exercise, vol. 48, no. 11, pp. 2320-2334, 2016.

[47] F. Péronnet, G. Thibault, E. C. Rhodes, and D. C. McKenzie, "Correlation between ventilatory threshold and endurance capability in marathon runners," Medicine \& Science in Sports \& Exercise, vol. 19, no. 6, pp. 610-615, 1987.

[48] H. Vandewalle, "A nomogram of performances in endurance running based on logarithmic model of péronnet-thibault," American Journal of Engineering Research (AJER), vol. 6, pp. 7885, 2017.

[49] G. A. Gaesser, T. J. Carnevale, A. Garfinkel, D. O. Walter, and C. J. Womack, "Estimation of critical power with nonlinear and linear models," Medicine \& Science in Sports \& Exercise, vol. 27, no. 10, pp. 1430-1438, 1995.

[50] T. J. Housh, J. T. Cramer, A. J. Bull, G. O. Johnson, and D. J. Housh, "The effect of mathematical modelling on critical velocity," European Journal of Applied Physiology, vol. 84, no. 5, pp. 469-475, 2001.

[51] A. J. Bull, T. J. Housh, G. O. Johnson, and S. R. Rana, "Physiological responses at five estimates of critical velocity," European Journal of Applied Physiology, vol. 102, no. 6, pp. 711720, 2008.

[52] H. C. Bergstrom, T. J. Housh, J. M. Zuniga et al., "Differences among estimates of critical power and anaerobic work capacity derived from five mathematical models and the three-minute all-out test," The Journal of Strength and Conditioning Research, vol. 28, no. 3, pp. 592-600, 2014.

[53] L. V. Billat and J. P. Koralsztein, "Significance of the velocity at VO2max and time to exhaustion at this velocity," Sports Medicine, vol. 22, no. 2, pp. 90-108, 1996.

[54] H. Vandewalle, "Mathematical modeling of the running performances in endurance exercises: comparison of the models of Kennelly and Péronnet-Thibaut for World records and elite endurance runners," American Journal of Engineering Research (AJER), vol. 6, no. 9, pp. 317-323, 2017.

[55] B. Zinoubi, H. Vandewalle, and T. Driss, "Modeling of running performances in humans: comparison of power laws and critical speed," The Journal of Strength and Conditioning Research, vol. 31, no. 7, pp. 1859-1867, 2017.

[56] F. X. Gamelin, J. Coquart, N. Ferrari et al., "Prediction of onehour running performance using constant duration tests," The Journal of Strength and Conditioning Research, vol. 20, no. 4, pp. 735-739, 2006.

[57] L. Bosquet, A. Duchene, F. Lecot, G. Dupont, and L. Leger, "Vmax estimate from three-parameter critical velocity models: 
Validity and impact on $800 \mathrm{~m}$ running performance prediction," European Journal of Applied Physiology, vol. 97, no. 1, pp. 34-42, 2006.

[58] M. Burnley and A. M. Jones, "Power-duration relationship: Physiology, fatigue, and the limits of human performance," European Journal of Sport Science, vol. 18, no. 1, pp. 1-12, 2018.

[59] M. L. Pepper, T. J. Housh, and G. O. Johnson, "The accuracy of the critical velocity test for predicting time to exhaustion during treadmill running," International Journal of Sports Medicine, vol. 13, no. 2, pp. 121-124, 1992.

[60] S.-I. Florence and J. P. Weir, "Relationship of critical velocity to marathon running performance," European Journal of Applied Physiology, vol. 75, no. 3, pp. 274-278, 1997.

[61] M. Kachouri, H. Vandewalle, V. L. Billat et al., "Critical velocity of continuous and intermittent running exercise. An example of the limits of the critical power concept," European Journal of Applied Physiology and Occupational Physiology, vol. 73, no. 5, pp. 484-487, 1996.

[62] R. Graubner and E. Nixdorf, "Biomechanical analysis of the sprint and hurdles events at the iaaf world championships in athletics," New Studies in Athletics, vol. 26, no. 1-2, pp. 19-53, 2009.

[63] H. Vandewalle, "Application of kennellymodel of running performances to elite endurance runners," Research Inventy: International Journal of Engineering and Science, vol. 7, pp. 1216, 2017. 


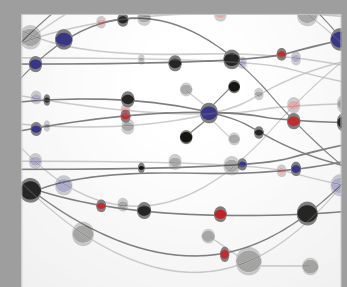

The Scientific World Journal
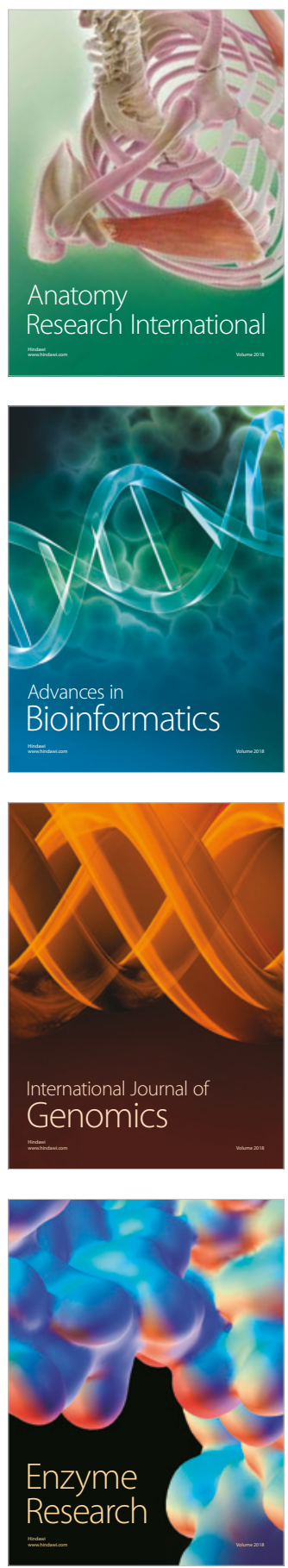
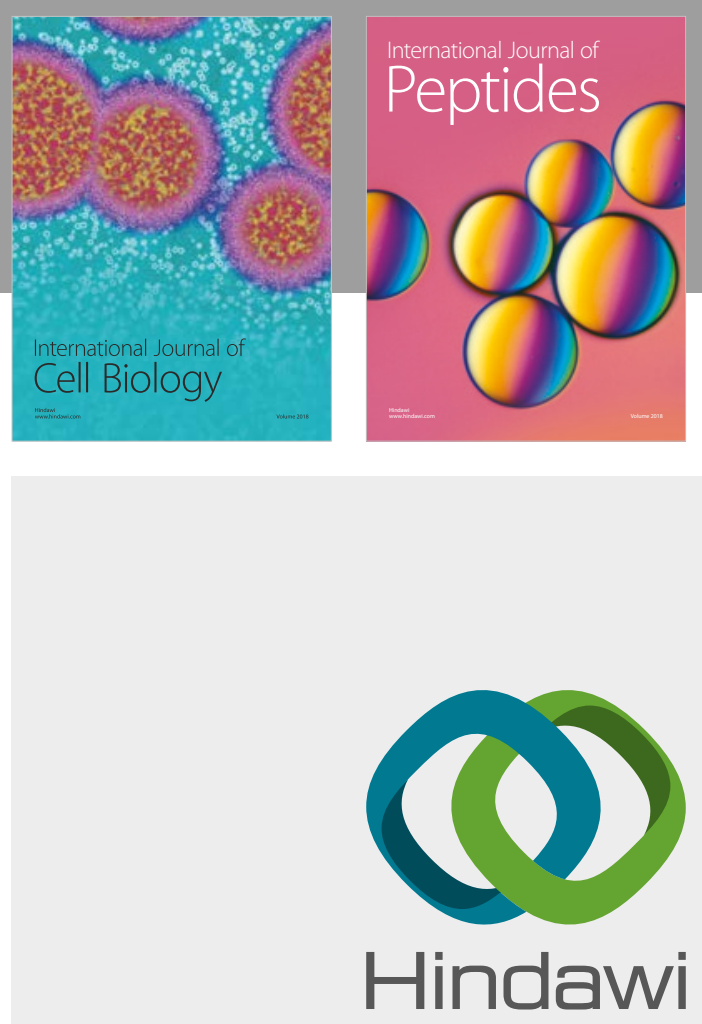

Submit your manuscripts at

www.hindawi.com
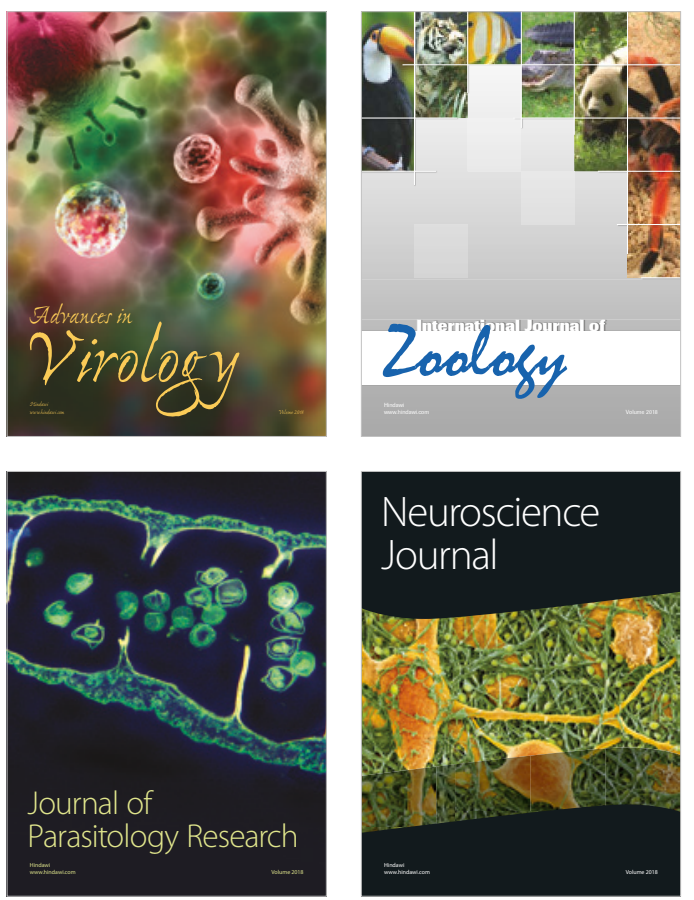
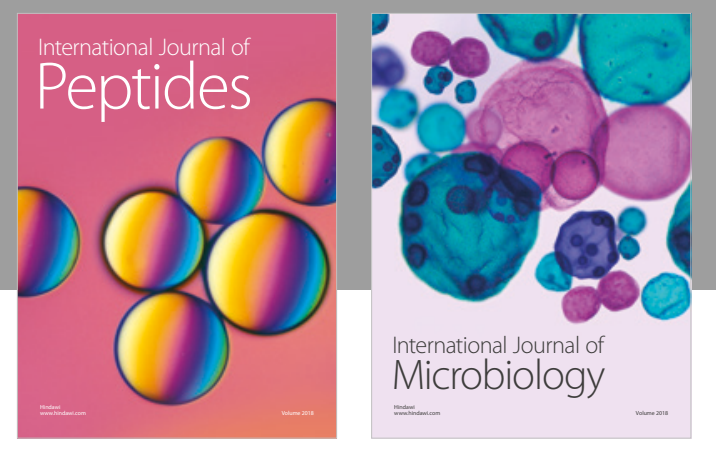

nternational Journal of Microbiology
Journal of
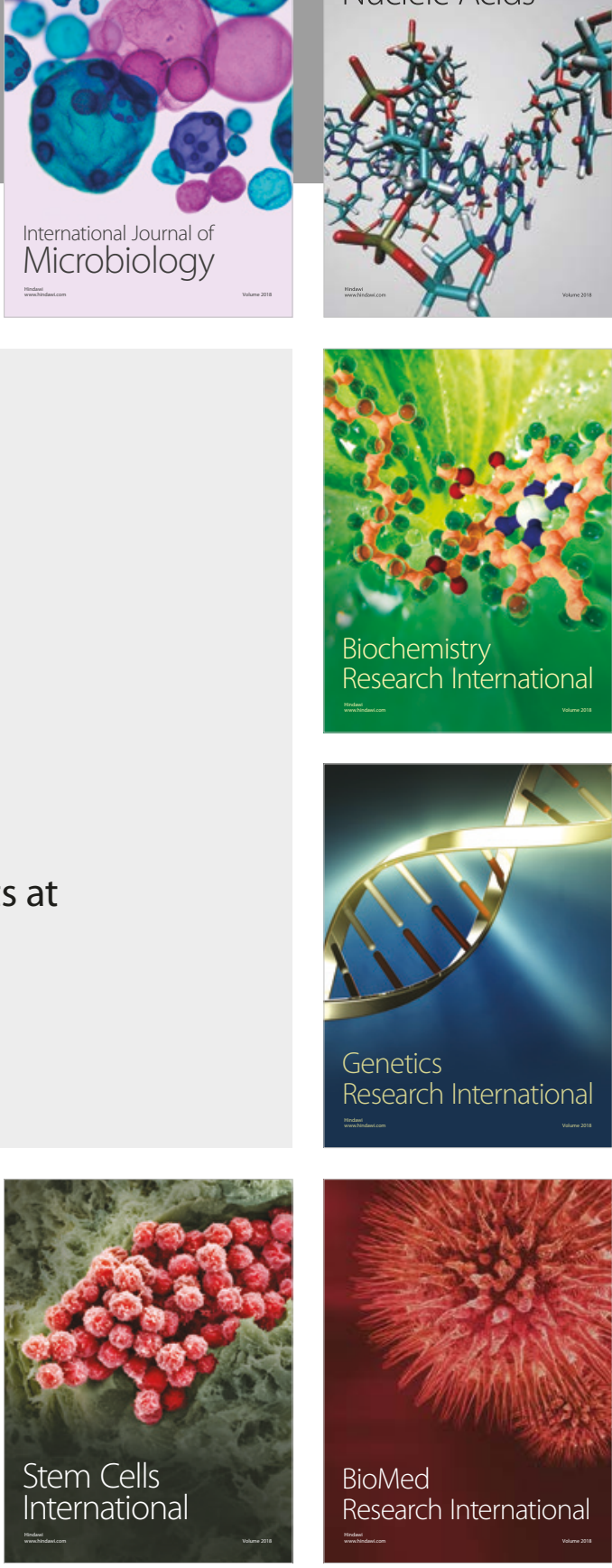
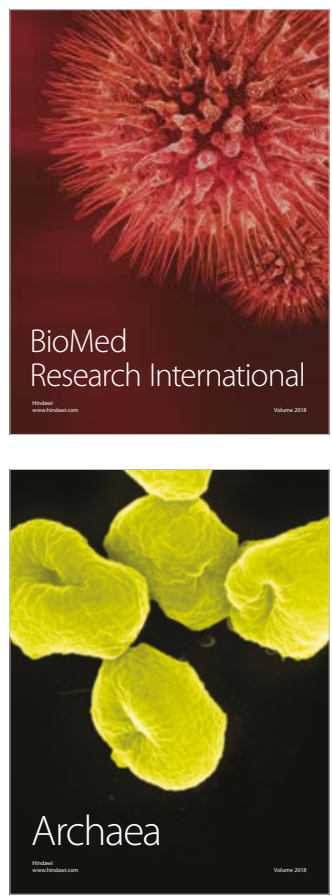